\title{
Turbulence Adjustment and Scaling in an Offshore Convective Internal Boundary Layer: A CASPER Case Study
}

\author{
QINGFANG JIANG \\ Naval Research Laboratory, Monterey, California \\ QING WANG \\ Naval Postgraduate School, Monterey, California \\ SHOUPING WANG AND SAŠA GABERŠEK \\ Naval Research Laboratory, Monterey, California
}

(Manuscript received 17 July 2019, in final form 18 February 2020)

\begin{abstract}
The characteristics of a convective internal boundary layer (CIBL) documented offshore during the East Coast phase of the Coupled Air-Sea Processes and Electromagnetic Ducting Research (CASPER-EAST) field campaign has been examined using field observations, a coupled mesoscale model (i.e., Navy's COAMPS) simulation, and a couple of surface-layer-resolving large-eddy simulations (LESs). The Lagrangian modeling approach has been adopted with the LES domain being advected from a cool and rough land surface to a warmer and smoother sea surface by the mean offshore winds in the CIBL. The surface fluxes from the LES control run are in reasonable agreement with field observations, and the general CIBL characteristics are consistent with previous studies. According to the LESs, in the nearshore adjustment zone (i.e., fetch $<8 \mathrm{~km}$ ), the low-level winds and surface friction velocity increase rapidly, and the mean wind profile and vertical velocity skewness in the surface layer deviate substantially from the Monin-Obukhov similarity theory (MOST) scaling. Farther offshore, the nondimensional vertical wind shear and scalar gradients and higher-order moments are consistent with the MOST scaling. An elevated turbulent layer is present immediately below the CIBL top, associated with the vertical wind shear across the CIBL top inversion. Episodic shear instability events occur with a time scale between 10 and $30 \mathrm{~min}$, leading to the formation of elevated maxima in turbulence kinetic energy and momentum fluxes. During these events, the turbulence kinetic energy production exceeds the dissipation, suggesting that the CIBL remains in nonequilibrium.
\end{abstract}

\section{Introduction}

Monin-Obukhov similarity theory (MOST) is widely used in numerical weather prediction models to provide lower boundary conditions, and in radio wave propagation models to characterize the atmospheric environment in the marine surface layer. While MOST has been extensively tested with field observations over relatively homogeneous land surfaces (e.g., Businger et al. 1971; Dyer 1974; Foken and Skeib 1983), its validity over ocean remains an open question. The similarity relationships for scalars over open ocean under unstable atmospheric conditions had been evaluated by

Corresponding author: Qingfang Jiang, qingfang.jiang@nrlmry. navy.mil
Edson et al. (2004) using the measurements from the 2000 Fluxes, Air-Sea Interaction and Remote Sensing (FAIRS) experiment and 2001 Gas Exchange Experiment (GasEx). They found that the similarity relationships for scalars are valid within the marine surface layer above the wave boundary layer. On the other hand, MOST likely becomes invalid over waves or over nearshore areas especially when offshore winds prevail, where the homogenous or stationary surface assumption is violated. It has been observed that over a swell-dominated sea the momentum flux in the surface layer may become nearly zero (e.g., Smedman et al. 1994; Grachev and Fairall 2001), suggesting that it is inadequate to derive surface stress using the MOST-based flux-profile relationship over swell conditions. Based on their large-eddy simulations of neutral boundary layer flows over swell, 
Jiang et al. (2016) concluded that the similarity relationship for the mean wind shear breaks down over swell. In a more recent paper, Jiang (2020) has demonstrated that the similarity relationships for scalars become invalid over swell and the deviations from MOST predictions tend to be more significant under stable to neutral conditions and less so for a convective boundary layer.

Under the influence of offshore winds, the boundary layer flow experiences discontinuity in surface roughness and temperature, and MOST becomes questionable due to significant surface heterogeneity. Earlier studies of coastal marine boundary layers (MBL) had either focused on the internal boundary layer (IBL) depth or surface fluxes with a few exceptions. The term internal boundary layer is used to refer to the portion of the boundary layer that is directly influenced by a new underlying surface (e.g., Garratt 1990). The IBL associated with cooler air over a warmer sea surface [i.e., convective internal boundary layer (CIBL)] is often characterized by a shallow mixed layer capped by an elevated inversion. The thickening of CIBL with the offshore distance (or fetch) has been investigated by several researchers (e.g., Raynor et al. 1975, 1979; Chang and Braham 1991). The studies in the second category focused on the evaluation of air-sea momentum and scalar exchange coefficients (i.e., drag coefficient, and Stanton and Dalton numbers) using field measurements from offshore towers or low-flying research aircraft (e.g., Mahrt et al. 1998; Vickers et al. 2001; Vickers and Mahrt 2010). Turbulence characteristics in an offshore IBL have been examined in a few observation-based studies. Shao and Hacker (1990) applied local similarity scaling to airborne measurements over a coastal area in the South Australia and concluded that the behavior of second and higher moments seem to be determined mainly by local forcing. Vickers and Mahrt (1999) assessed the nondimensional vertical wind shear from offshore tower observations and found that, in a shallow CIBL, the nondimensional wind shear tends to deviate from the MOST prediction, due to the suppression of largest eddies by the CIBL top. Grachev et al. (2018) analyzed observations from four meteorological towers, three over land on the coast and one located on the Duck Research Pier (DRP; extending $560 \mathrm{~m}$ over sea) during the East Coast phase of the Coupled Air-Sea Processes and Electromagnetic Ducting Research project [CASPER-EAST; see Wang et al. (2018) for details] period. They found that the observed standard deviations tend to follow the Monin-Obukhov similarity theory, while the nondimensional vertical gradients evaluated from multiple level measurements exhibit significantly larger scatter. They concluded that the flux-profile (or flux-gradient) relationships become questionable near shore (i.e., fetch $\sim 560 \mathrm{~m}$; Grachev et al. 2018), due to surface heterogeneity.

In addition to field observations, the IBL has been subject to several LES studies as well. In a pioneer study, Skyllingstad et al. (2005) demonstrated that their LES code was capable of reproducing general features of a stable IBL offshore of Duck, North Carolina, with reasonable agreement with aircraft observations. In a more recent study, Yang et al. (2019) simulated the coastal MBL under both onshore and offshore wind conditions near DRP using an LES code and found good agreement between their simulated winds and fluxes in the surface layer and near the coast (i.e., $\sim 1 \mathrm{~km}$ or less from the coastline) observations from CASPER-EAST.

This study is motivated by some CASPER-EAST observations that showed substantial deviations of the observed surface-layer profiles from their corresponding MOST predictions. The overarching objective is to shed light on the characteristics of a CIBL with particular emphasis on the adjustment of the marine surface layer with offshore distance and validity of MOST over coastal oceans. The rest of this paper is structured as follows. Section 2 includes discussion of the synoptic and mesoscale meteorological conditions and some field observations. The LES code, modeling strategy, and configuration are illustrated in section 3 . The LES results are presented in section 4 . Sections 5 and 6 include discussion of a number of key issues and concluding remarks, respectively.

\section{The 20 October case}

\section{a. CASPER-EAST observations}

The field observations of CASPER-EAST took place offshore of Duck, North Carolina, in the October and November of 2015. The objectives of CASPER-EAST are to advance the understanding of marine surfacelayer physics and to better characterize the MBL for radio wave propagation prediction. During the monthlong field campaign, a wealth of assets have been deployed approximately along $36.2^{\circ} \mathrm{N}$. The observational strategy, instruments, and some preliminary results were summarized in Wang et al. (2018). The focus of this study is on an offshore wind event documented from the late morning to early afternoon (i.e., 1300 1730 UTC) of 20 October 2015. During this period, seven radiosondes had been launched from DRP and two research vessels [i.e., R/V Hugh R. Sharp (HRS) and $\mathrm{R} / \mathrm{V}$ Atlantic Explorer, $(A E)]$, with offshore distance ranging from $\sim 3$ to $\sim 50 \mathrm{~km}$. The wind, temperature, and specific humidity profiles from these radiosondes are shown in Fig. 1. The winds are primarily southwesterlies 


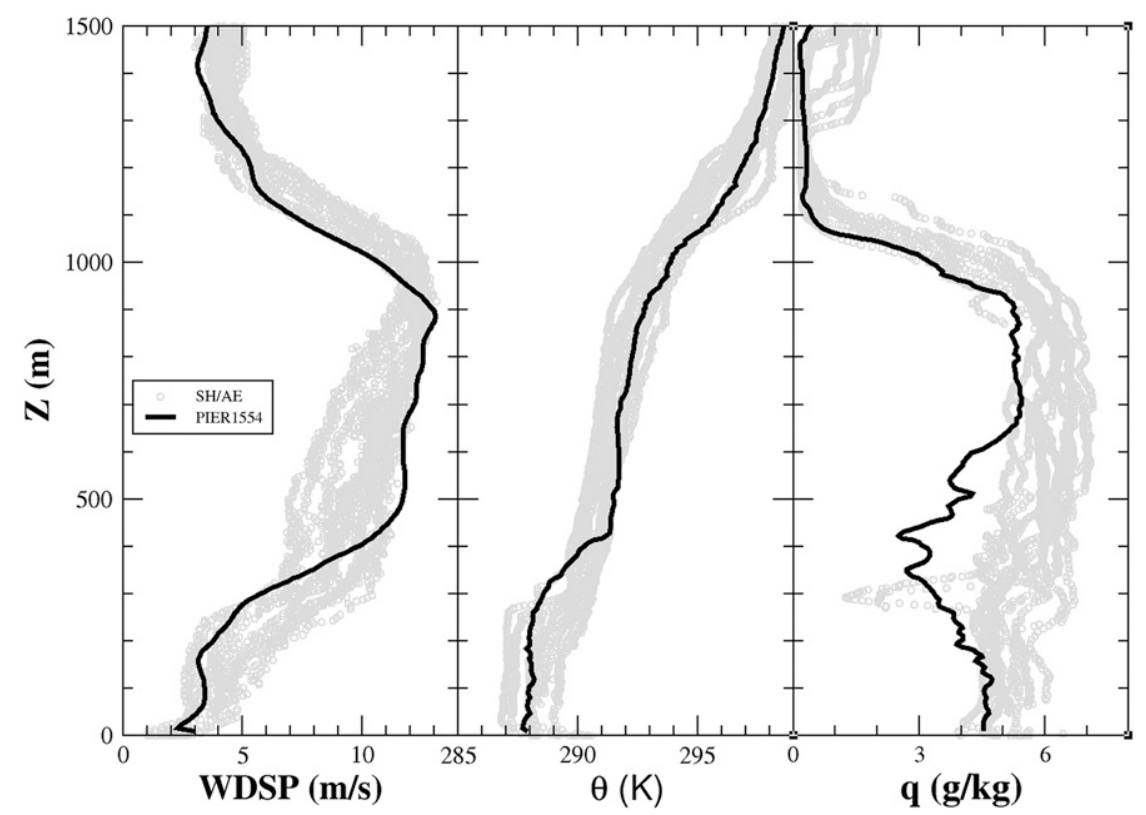

FIG. 1. (left) Wind speed (WDSP, $\left.\mathrm{m} \mathrm{s}^{-1}\right)$, (center) potential temperature $(\theta, \mathrm{K})$, and (right) specific humidity $\left(q, \mathrm{~g} \mathrm{~kg}^{-1}\right)$ profiles from a radiosonde launched from Duck Research Pier (DPR, bold black curves) and six radiosondes from R/V Sharp and Atlantic (gray circles) approximately between 1400 and 1730 UTC (i.e., 1000-1330 LST). The two research vessels cruised approximately along $36.2^{\circ} \mathrm{N}$ during this period.

during this time period. A relatively weak inversion $(2-4 \mathrm{~K})$ is located between 200 and $500 \mathrm{~m}$, revealed by all the soundings with the inversion height and strength exhibiting noticeable variations. Underneath the inversion, the atmosphere appears to be well mixed, evidenced in the relatively uniform wind speed, potential temperature and specific humidity profiles, suggesting the existence of a well-defined CIBL. Substantial vertical wind shear exists across the low-level inversion with wind speed increasing from 3 to $4.5 \mathrm{~m} \mathrm{~s}^{-1}$ within the CIBL to $11 \mathrm{~m} \mathrm{~s}^{-1}$ above the inversion. The specific humidity is characterized by a minimum resided in the inversion and larger values above and below the inversion. Aloft, a stronger inversion is located between 1200 and $1500 \mathrm{~m}$, above which the air is drier and wind speed is much weaker.

The shallow well-mixed layer in the sounding profiles is consistent with the negative air-sea temperature difference $\left(\Delta T_{\mathrm{as}}=-4.6 \mathrm{~K}\right.$; i.e., sea surface is warmer than low-level air) and positive sensible heat flux (Table 1) sampled from the bow mast of R/V Sharp at $36.19^{\circ} \mathrm{N}$, $-75.428^{\circ} \mathrm{W}$ [i.e., approximately $28.5 \mathrm{~km}$ offshore; see Wang et al. (2018) for details]. One unique dataset from CASPER-EAST is the high-vertical-resolution measurements of potential and specific humidity in the marine surface layer using a tethered-balloonbased surface-layer profiling system [also referred to as Marine Atmospheric Profiling System (MAPS)]. The measurements were taken from a small boat to minimize possible contamination from the platform itself. The blue dots in Fig. 2 correspond to the MAPS measurements collected during multiple ups and downs over a period of $30-45 \mathrm{~min}$ and the red curves are the bin-averaged mean profiles along with the corresponding similarity theory predictions (i.e., green lines) using the COARE 3.0 algorithm (Fairall et al. 2003) and the fluxes simultaneously measured over $H R S$ for comparison. There are noticeable differences between the observed mean profiles and the corresponding COARE curves, suggesting that MOST may not be valid at the observational location. The significance of these differences can be seen from the modified refractivity $(M)$

TABLE 1. Surface fluxes and derived parameters measured from R/V Sharp at approximately 1314 UTC and $28.5 \mathrm{~km}$ offshore.

\begin{tabular}{lcccc}
\hline \multicolumn{1}{c}{ Obs/LES } & $T_{\text {as }}(\mathrm{K})$ & $\mathrm{MF}\left(\mathrm{N} \mathrm{m}^{-2}\right)$ & $\mathrm{SHF}\left(\mathrm{W} \mathrm{m}^{-2}\right)$ & $\mathrm{LHF}\left(\mathrm{W} \mathrm{m}{ }^{-2}\right)$ \\
\hline HRS & -4.68 & -0.032 & 31.35 & 105.4 \\
LES: CNTROL & -4.61 & -0.031 & 30.85 & 107.5 \\
LES: NOSHEAR & -4.74 & -0.0235 & 28.67 & 114.0 \\
\hline
\end{tabular}



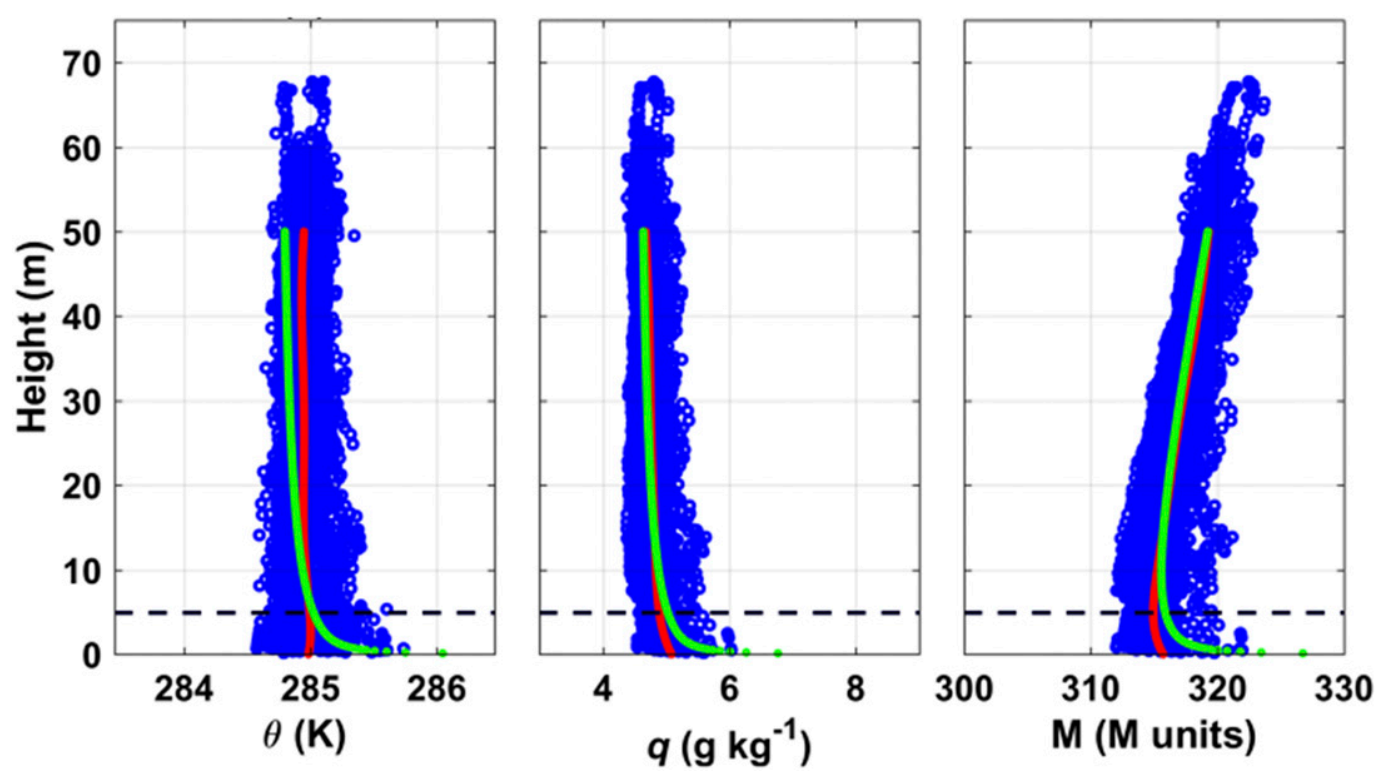

FIG. 2. (left) Potential temperature (K), (center) specific humidity $\left(\mathrm{g} \mathrm{kg}^{-1}\right)$, and (right) modified refractivity ( $M$ units) profiles derived from the MAPS measurements (i.e., blue circles). Also shown are the bin-averaged profiles (red curve) and the corresponding similarity theory predictions using the TOGA COARE 3.0 formula.

profile, calculated from the following empirical equation (e.g., Bean and Dutton 1968),

$$
M=\frac{77.6}{T}\left(P+\frac{4810 e}{T}\right)+0.157 z
$$

where $T$ is the air temperature $(\mathrm{K}), e$ and $P$ denote the water vapor and total atmospheric pressure $(\mathrm{hPa})$, and $z$ is the height above the sea surface. The modified refractivity is an important parameter for predicting radio wave propagation in the atmosphere. While generally, $M$ tends to increase with height in the troposphere, evaporation ducts (ED; i.e., a downward refracting layer immediately above the sea surface for radio waves) are virtually ubiquitous over sea, in accordance to the decrease of $M$ with height associated with a strong negative specific humidity gradient. The top of an ED corresponds to a minimum in $M$ in the marine surface layer. As shown in Fig. 2c, the ED top based on the observed mean profiles is located approximately at $5 \mathrm{~m}$ above sea surface (MSL), and the MOST predicted ED top is approximately at $15 \mathrm{~m}$ MSL. The difference between the two is dramatic, considering that a few-meter error in the ED height may lead to considerable errors in radio wave propagation prediction (e.g., Konstanzer 1994). According to previous studies, MOST may become invalid over a heterogeneous surface such as near a coastline (Grachev et al. 2018) or over a nonstationary surface (e.g., Jiang 2020). However, the sea waves were relatively weak during this time period in accordance with the low winds in the surface layer, and no significant swell was documented. The MAPS sampling site is located approximately $28.5 \mathrm{~km}$ offshore instead of being immediately offshore as those analyzed in Grachev et al. (2018). A question arises as to whether at the observational site the surface layer was still influenced by the upstream heterogeneity, or more broadly, how far offshore is far enough for MOST to be valid.

\section{b. COAMPS simulation and meteorological conditions}

The U.S. Navy's Coupled Ocean-Atmospheric Mesoscale Prediction System (COAMPS; ${ }^{1}$ Hodur 1997; Chen et al. 2010) had been applied to the CASPEREAST area to provide guidance during the field observation period. Reasonable agreement was found between real-time COAMPS predictions and CASPER observations (Ulate et al. 2019). To understand the synoptic and mesoscale meteorological conditions on 20 October 2015, this case has been simulated using COAMPS with a higher resolution. The physical parameterizations and model configuration of this simulation are further described in the appendix.

Shown in Fig. 3 are snapshots of the sea surface temperature (SST), surface and 200-m winds, and latent and sensible heat fluxes from the COAMPS simulation valid

\footnotetext{
${ }^{1}$ COAMPS is a registered trademark of the Naval Research Laboratory.
} 

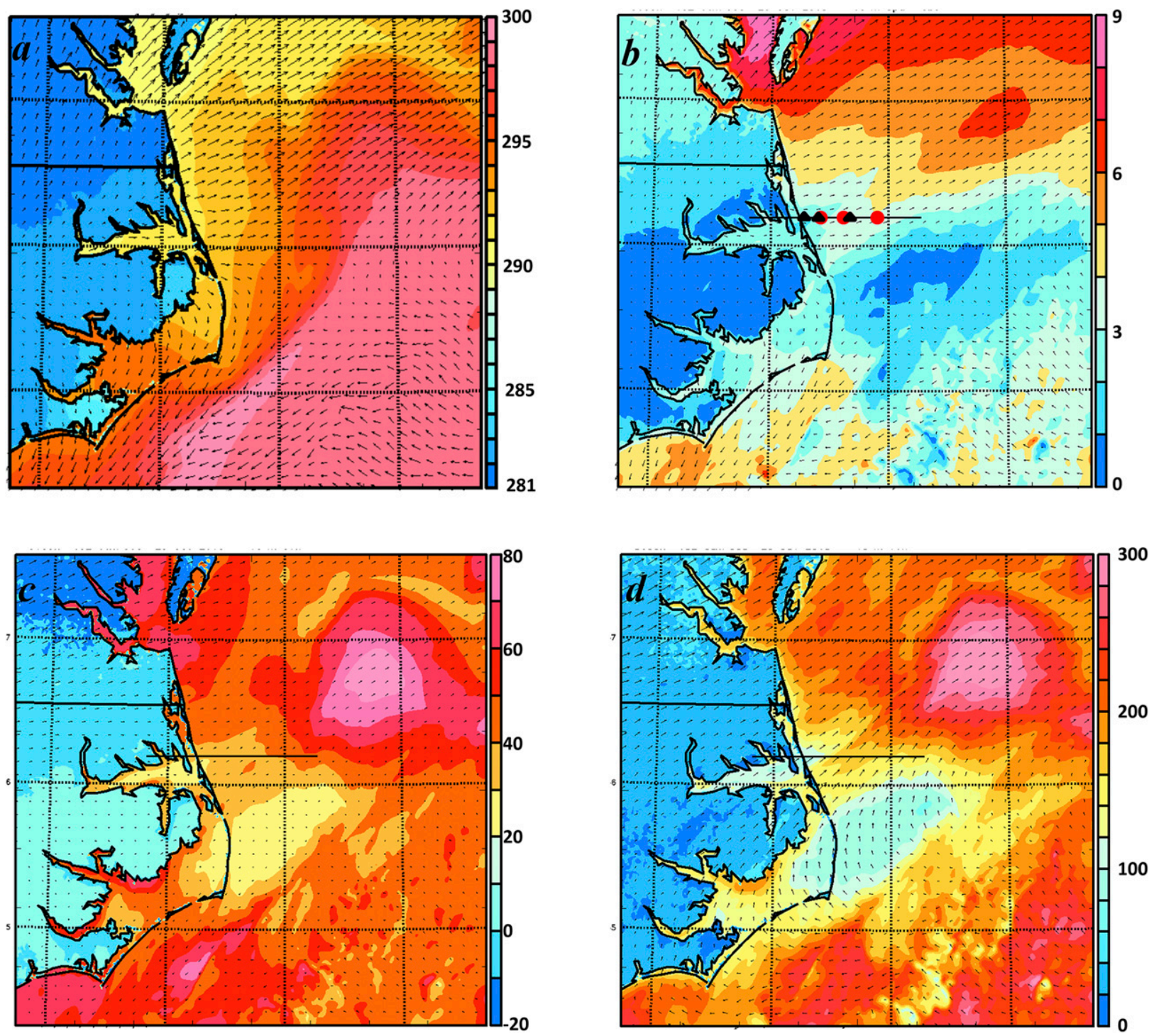

FIG. 3. Plan-views of (a) sea surface temperature (SST, colors, increment $=1 \mathrm{~K}$ ) and 10-m wind vectors, (b) 10-m wind speed (colors, increment $=1 \mathrm{~m} \mathrm{~s}^{-1}$ ) along with wind vectors at $200 \mathrm{~m}$, (c) surface sensible heat flux (colors, increment $=5 \mathrm{~W} \mathrm{~m}{ }^{-2}$ ) along with wind vectors at $400 \mathrm{~m} \mathrm{MSL}$, and (d) surface latent heat flux (colors, increment $=20 \mathrm{~W} \mathrm{~m}^{-2}$ ) along with 600-m wind vectors, from the COAMPS $1-\mathrm{km}$ grid valid at 1400 UTC 20 Oct 2015. The locations of the research vessels when the radiosondes were launched are shown as black triangles and red circles in (b).

at 1400 UTC 20 October 2015. The prevailing winds in the BL are west-southwesterlies (WSW) to southwesterlies (SW) in the lowest $200 \mathrm{~m}$. At 1400 UTC (i.e., $1000 \mathrm{EST}$ ), the land surface is about $5^{\circ} \mathrm{C}$ cooler than the SST near shore and SST tends to increase with the offshore distance at a rate of approximately $0.5 \mathrm{~K}(10 \mathrm{~km})^{-1}$ along $36.2^{\circ} \mathrm{N}$. The sensible heat flux is around $30 \mathrm{~W} \mathrm{~m}^{-2} \mathrm{im}-$ mediately offshore, becomes progressively larger with offshore distance, and is approximately $40 \mathrm{~W} \mathrm{~m}^{-2}$ at $X=$ $50 \mathrm{~km}$ ( $X$ here denotes the offshore distance along $36.2^{\circ} \mathrm{N}$ ). The latent heat flux increases from 100 to $120 \mathrm{~W} \mathrm{~m}^{-2}$ near shore to $\sim 150 \mathrm{~W} \mathrm{~m}^{-2}$ at $X=50 \mathrm{~km}$. The simulated sensible and latent heat fluxes as well as the surface stress (not shown) are in reasonable agreement with the flux observations at the R/V Sharp mast.

The development of a CIBL is evident in the vertical cross sections (Fig. 4), which show a shallow stable layer over land and a well-mixed layer over sea capped by an inversion. The zonal winds are weaker within CIBL and substantially stronger aloft approximately up to $1.2 \mathrm{~km}$ MSL as observed by the radiosondes (Fig. 1). The CIBL depth grows with the offshore distance approximately as $Z_{i}=a \sqrt{X+X_{0}}$, where $X_{0}=4000 \mathrm{~m}$ (here $X$ and $Z_{i}$ are in meters) with the coefficient $a=1.6 \mathrm{~m}^{1 / 2}$, which is in 

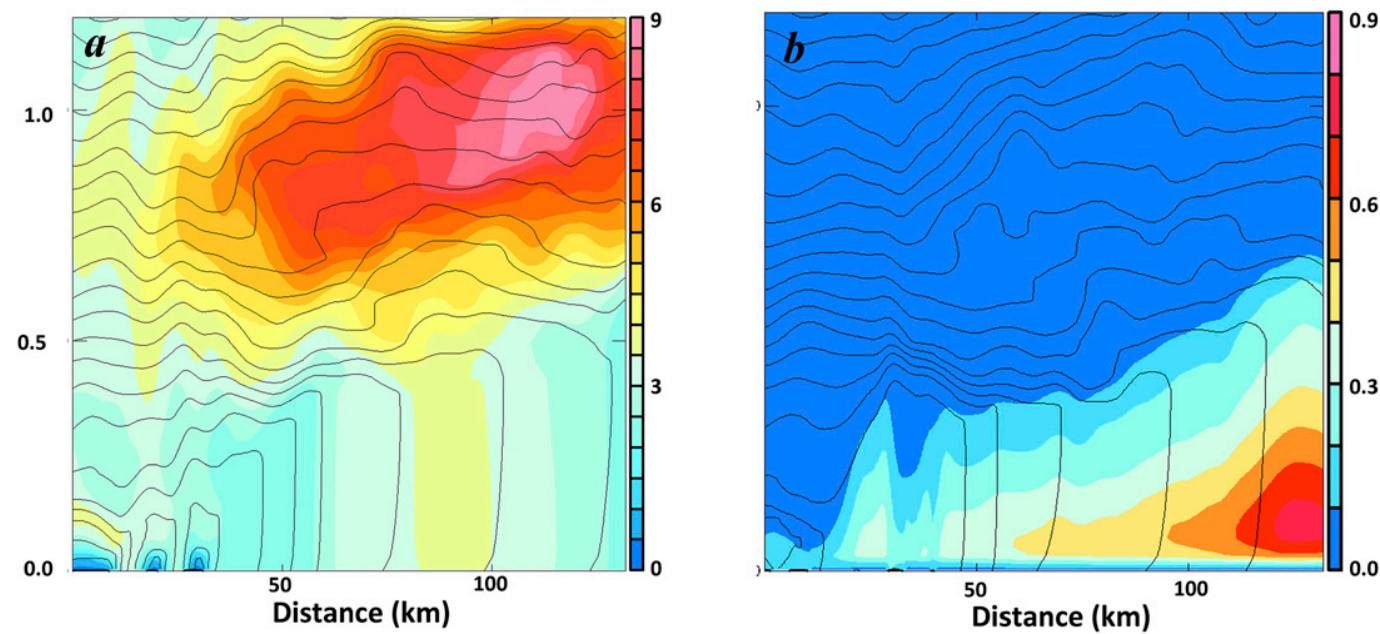

FIG. 4. Vertical cross sections of (a) zonal wind $u$ (colors, increment $=0.5 \mathrm{~m} \mathrm{~s}^{-1}$ ) oriented along $36.2^{\circ} \mathrm{N}$ valid at 1300 UTC and (b) TKE (colors, increment $=0.1 \mathrm{~m}^{2} \mathrm{~s}^{-2}$ ) valid at $1400 \mathrm{UTC}$. The corresponding potential temperatures are contoured with an increment $=0.5 \mathrm{~K}$. The zonal distance ranges from $-30 \mathrm{~km}$ (i.e., $30 \mathrm{~km}$ inland) to $100 \mathrm{~km}$ and only the lowest $1.2 \mathrm{~km}$ is shown.

qualitative agreement with those derived from field observations (e.g., Hsu 1986). The square-root dependence of a CIBL depth on the offshore distance has been suggested by several other studies (e.g., Raynor et al. 1975; Garrat 1990; Chang and Braham 1991).

\section{Large-eddy simulation code and Lagrangian approach}

To deepen our understanding of the turbulence adjustment in the CIBL to the land-sea surface transition, we have conducted a couple of high-resolution LES using the Lagrangian approach illustrated below.

\section{a. LES code}

The LES code solves the following spatially filtered Boussinesq equations in a rectangular domain (e.g., Moeng 1984; Sullivan et al. 2014):

$$
\begin{gathered}
\frac{\partial u_{i}}{\partial x_{i}}=0 \\
\frac{\partial u_{i}}{\partial t}+\frac{\partial u_{j} u_{i}}{\partial x_{j}}=-\frac{\partial p^{*}}{\partial x_{i}}-\frac{\partial \tau_{i j}}{\partial x_{j}}-\varepsilon_{i j k} f_{j} u_{k}-\frac{\partial P}{\partial x_{i}} \\
+\delta_{i 3} \frac{g}{\theta_{v 0}}\left(\theta_{v}-\theta_{v 0}\right), \\
\frac{\partial \theta}{\partial t}+\frac{\partial u_{i} \theta}{\partial x_{i}}=-\frac{\partial \tau_{i \theta}}{\partial x_{i}}, \\
\frac{\partial q}{\partial t}+\frac{\partial u_{i} q}{\partial x_{i}}=-\frac{\partial \tau_{i q}}{\partial x_{i}},
\end{gathered}
$$

$$
\frac{\partial e}{\partial t}+\frac{\partial\left(u_{i} e\right)}{\partial x_{i}}=-\tau_{i j} S_{i j}+\frac{g}{\theta_{0}} \tau_{3 \theta}+\frac{\partial}{\partial x_{j}}\left(2 \nu \frac{\partial e}{\partial x_{j}}\right)-\varepsilon .
$$

The prognostic variables include the three Cartesian wind components, $u_{i}=(u, v, w)$, potential temperature $\theta$, the air density-normalized perturbation pressure, $p^{*}=p / \rho_{0}(p$ is the perturbation pressure and $\rho_{0}$ is the air density), specific humidity $q$, and the subgrid-scale (SGS) turbulence kinetic energy $e$. The other symbols are the density-normalized external (i.e., synoptic scale or mesoscale) pressure gradient, $\partial P / \partial x_{i}=\left(-f V_{g}, f U_{g}, 0\right)$, the Coriolis coefficients, $f_{i}=$ $(0,0, f)$, the reference potential temperature $\theta_{0}$, virtual potential temperature, $\theta_{v}=\theta(1+0.61 q)$, strain rates, $S_{i j}=$ $\left(\partial u_{i} / \partial x_{j}+\partial u_{j} / \partial x_{i}\right) / 2$, turbulence kinetic energy (TKE) dissipation rate $\varepsilon$, and the SGS momentum, potential temperature, and water vapor fluxes, $\tau_{i j}, \tau_{i \theta}$, and $\tau_{i q}$. The two-part SGS eddy-viscosity model illustrated in Sullivan et al. (1994) is employed for evaluation of the SGS fluxes and dissipation rate. The difficulty for LES models with the widely used Smagorinsky SGS scheme to produce mean wind and scalar gradients near the surface in consistency with MOST has been addressed in several previous studies (e.g., Mason and Thomson 1992). It has been demonstrated in Sullivan et al. (1994) that the two-part SGS model is able to produce mean wind and temperature gradients in better agreement with MOST in the surface layer. More details of the LES code can be found in Moeng (1984) and Sullivan et al. (2014).

\section{b. Lagrangian approach and LES configuration}

It is still computationally infeasible to have an LES domain large enough to properly simulate the land-sea 
transition and offshore variation of the MBL with grid spacings fine enough to adequately resolve surface-layer processes. For example, several CASPER-EAST cases had been simulated by Yang et al. (2019) using an LES code with a domain of $2.75 \mathrm{~km}$ long and $250 \mathrm{~m}$ deep. Although it has been demonstrated that there is a reasonable agreement between the simulated winds and fluxes in the nearshore surface layer and the corresponding field observations, such a domain size is apparently too small for examining offshore variations of an IBL. Therefore, as a compromise, we adopt the Lagrangian modeling approach, which allows us to simulate the development of the internal boundary layer and turbulence adjustment over a substantial offshore distance (i.e., $\sim 100 \mathrm{~km}$ ) at an affordable computational cost. The Lagrangian modeling approach has been frequently used in air pollution modeling (e.g., Zannetti 1990; Hertwig et al. 2015) and large-eddy simulation (or single-column model) studies of cloud transition over a substantial meridional distance (e.g., Schubert et al. 1979; de Szoeke and Bretherton 2004; Yamaguchi et al. 2017).

Specifically, the horizontal LES domain for this study is a square with sides $L_{x}=L_{y}=1.536 \mathrm{~km}$ and a grid spacing of $3 \mathrm{~m}$. Periodic conditions applied to the lateral boundaries. There are 160 vertical levels with the model top located at $900 \mathrm{~m}$ where a radiation boundary condition is applied (Klemp and Durran 1983) to minimize downward reflection of internal gravity waves. The vertical grid spacing increases from $1 \mathrm{~m}$ at the first model level to $\sim 11.8 \mathrm{~m}$ near the model top with a constant stretching ratio $\Delta z_{i+1} / \Delta z_{i}=1.013$. The LES model is initialized with potential temperature, wind, and specific humidity profiles modified from DRP sounding profiles. Specifically, the zonal wind is $4 \mathrm{~m} \mathrm{~s}^{-1}$ below $200 \mathrm{~m}$ and $11 \mathrm{~m} \mathrm{~s}^{-1}$ at $550 \mathrm{~m}$ and above, and linearly increases between the two levels. The meridional wind component is $V_{g}=1 \mathrm{~m} \mathrm{~s}^{-1}$ independent of height. Geostrophic balance is enforced for the mean winds. The potential temperature is $284 \mathrm{~K}$ below $200 \mathrm{~m}$, linearly increases to $288 \mathrm{~K}$ between 200 and $550 \mathrm{~m}$, and linearly increases with height as $3 \mathrm{~K} \mathrm{~km}^{-1}$ aloft. The specific humidity linearly decreases from 5.3 at $1 \mathrm{~m}$ to $2.3 \mathrm{~g} \mathrm{~kg}^{-1}$ at $400 \mathrm{~m}$ and then increases to $6.3 \mathrm{~g} \mathrm{~kg}^{-1}$ at $680 \mathrm{~m}$. The LES domain is advected first over land and then offshore with the mean zonal winds in CIBL [i.e., $\bar{U}(t)=\left(1 / Z_{i} L_{x} L_{y}\right) \int_{0}^{Z_{i}} \int_{0}^{L_{x}} \int_{0}^{L_{y}} u(x, y, z, t) d x d y d z$, where $Z_{i}$ denotes the CIBL depth]. The surface stress, sensible heat flux and latent heat flux are evaluated using MOST with the wind speed, temperature, and specific humidity at the first model level. The surface roughness length, surface temperature, and saturation specific humidity vary with time to mimic the transition from a cold, rough, and dry land surface to a warmer, smoother, and more moist sea surface. Specifically, the surface roughness for momentum is $0.05 \mathrm{~m}$ over land for the first $3 \mathrm{~h}$ $25 \mathrm{~min}, 0.1 \mathrm{~mm}$ over sea after $3.5 \mathrm{~h}$, and, for the sake of simplicity, linearly interpolated between the two over a 5-min transition zone during which the LES domain is partially over water and partially over land. The surface temperature is $283.5 \mathrm{~K}$ over land and $289 \mathrm{~K}$ over the water surface immediately offshore. Farther offshore, the SST increases with the offshore distance by $0.05 \mathrm{~K} \mathrm{~km}^{-1}$ in accordance to the COAMPS simulation. The roughness lengths for the potential temperature $z_{\theta 0}$ and specific humidity $z_{q 0}$ are 0.05 and $0.02 \mathrm{~mm}$, respectively. The choice of smaller roughness lengths for temperature and moisture is based on several coarser-resolution experimental LESs to best match the observed stress and sensible and latent heat fluxes. It is worth noting that Vickers and Mahrt (2010) found, from tower and ship measurements, that the sea surface is smoother for moisture, that is, $z_{q 0}<z_{\theta 0}$, over a midlatitude coastal zone.

A few aspects of the LES configuration are worth noting here. First, the LES domain used in this study is relatively small and shallow for studying a typical convective boundary layer. The choice is made based on the observed lower inversion height, which ranges between 200 and $500 \mathrm{~m}$, suggesting that the CIBL is shallow over the study area. In a test simulation with identical configuration except that the horizontal grid spacing and the domain size are doubled, the general features of the simulated CIBL are in reasonable agreement with the control simulation. The use of the finer grid spacing aims to better resolve the surface layer, and for the same reason, the computationally more costly two-part SGS model described in Sullivan et al. (1994) is employed to better represent the underresolved turbulence near the surface. Second, for simplicity, the surface roughness lengths over sea are constant for this study, although some previous studies suggested that the surface roughness over coastal areas may vary with wind speed, wave states, and the fetch. Third, the integration time can be converted into the offshore distance using $X=\int_{t_{0}}^{t} \bar{U} d t$, where $t_{0}=12600 \mathrm{~s}$ is the time when the land-sea transition occurs and $\bar{U}$ denotes the mean zonal wind component vertically averaged over the CIBL. Finally, in addition to the "control" simulation (referred to as CONTROL hereafter), a sensitivity simulation has been conducted with the LES configured identical to CONTROL except that the wind shear across the inversion has been removed from the initial wind profile (referred to NOSHEAR hereafter). The objective of the NOSHEAR simulation is to examine the influence of the elevated shear layer on the CIBL and especially the marine 
Time (h)

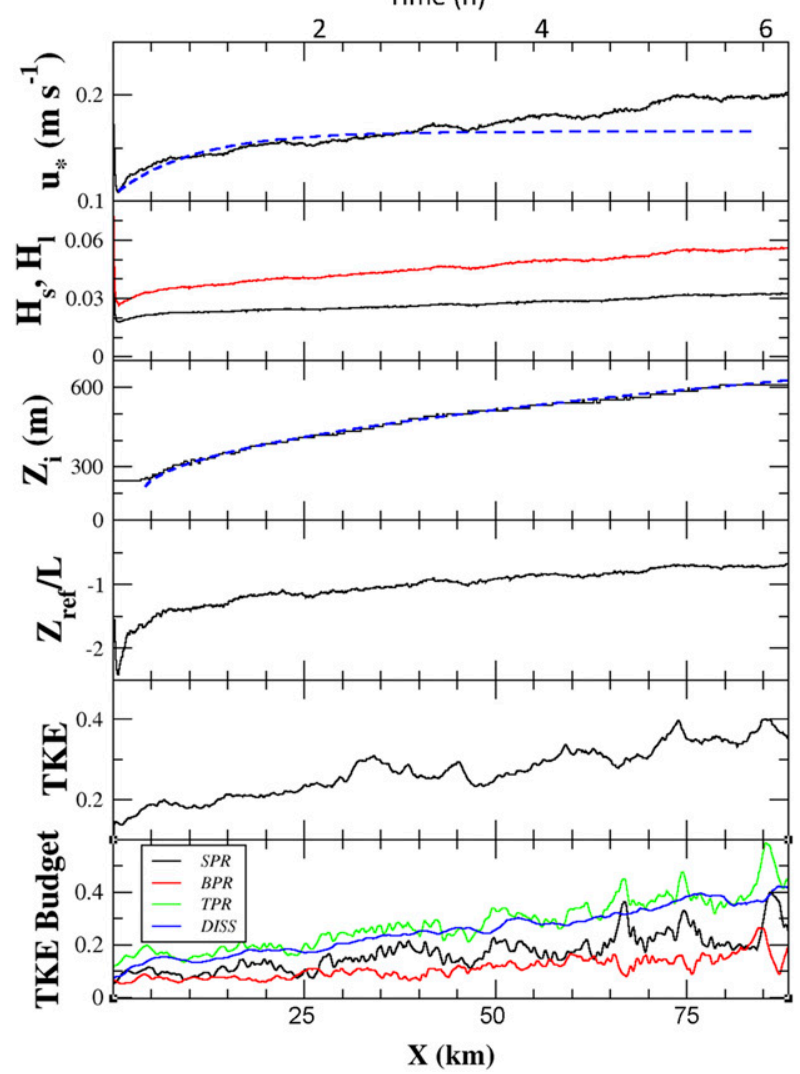

FIG. 5. Offshore variations of (top to bottom) the domainaveraged friction velocity $\left(u_{*}, \mathrm{~m} \mathrm{~s}^{-1}\right)$, sensible and latent heat fluxes $\left(H_{s}, \mathrm{~K} \mathrm{~m} \mathrm{~s}^{-1}\right.$; and $\left.H_{l}, \mathrm{~g} \mathrm{~kg}^{-1} \mathrm{~m} \mathrm{~s}^{-1}\right)$, BL height $\left(Z_{i}, \mathrm{~m}\right)$, stability parameter $\left(Z_{\mathrm{ref}} / L\right)$, vertically integrated total TKE $\left(\mathrm{m}^{3} \mathrm{~s}^{-2}\right)$, and TKE production and dissipation terms $\left[\mathrm{m}^{2} \mathrm{~s}^{-3}\right.$; shear production rate (SPR), buoyancy production rate (BPR), total production rate $(\mathrm{TPR}=\mathrm{SPR}+\mathrm{BPR})$ and dissipation rate (DISS)]. The horizontal axis is offshore distance $(X, \mathrm{~km})$ with the travel time (h) labeled along the top. The dashed-blue curves in the top and third rows correspond to $u_{*}(x)=u_{*_{m}}+\Delta u_{*}\left(1-e^{-X / L_{R}}\right)$ with $L_{R}=$ $8 \mathrm{~km}$ and $Z_{i}=1.85 \sqrt{X+X_{0}}$ with $X_{0}=3000 \mathrm{~m}$, respectively.

surface-layer characteristics, and the results are presented in section 6 .

\section{Characteristics of the CIBL}

In this section, we examine the general features of CIBL and associated turbulence characteristics from the control simulation. Shown in Fig. 5 are time series of the domain-averaged surface friction velocity $\left(u_{*}\right)$, internal boundary layer depth $\left(Z_{i}\right)$, sensible $\left(H_{s}\right)$ and latent heat $\left(H_{L}\right)$ fluxes, surface stability parameter [i.e., $Z_{\text {ref }} / L$, where $Z_{\text {ref }}=10 \mathrm{~m}$ and $L=-u_{*}^{3} \theta_{v} /\left(\kappa g w^{\prime} \theta_{v}^{\prime}\right)$ is the Obukhov length, where $g$ is the gravity acceleration and $\kappa=0.4$ is the von Kármán constant], the vertically integrated TKE, and vertically integrated turbulence production terms. Immediately offshore, the friction velocity drops to less than $0.1 \mathrm{~m} \mathrm{~s}^{-1}$ in accordance with the transition from the rough land surface to the much smoother sea surface, and then increases with the offshore distance toward a quasi-equilibrium value of $\sim 0.175 \mathrm{~m} \mathrm{~s}^{-1}$. The friction velocity is around $0.16 \mathrm{~m} \mathrm{~s}^{-1}$ at $X=28.5 \mathrm{~km}$ (i.e., the approximate MAPS and $\mathrm{R} / \mathrm{V}$ Sharp location when the measurements were made), which is in good agreement with the R/V Sharp measurements.

Over a "nearshore adjustment zone" (NAZ), a nearshore area where $u_{*}$ increases rapidly, the variation of $u_{*}$ can be approximated as $u_{*}(X)=u *_{m}+\Delta u_{*}\left(1-e^{-X / L_{R}}\right)$, where $\Delta u_{*}=u *_{E}-u *_{m}, u *_{m}$ denotes the friction velocity minimum near shore and $u *_{E} \approx 0.175 \mathrm{~m} \mathrm{~s}^{-1}$ is the equilibrium friction velocity far offshore, $L_{R}=8 \mathrm{~km}$, is the $e$-folding adjustment distance (or $e$-folding adjustment time $\sim 2250 \mathrm{~s}$ ). As the surface roughness length over sea is constant in this study, the increase in $u_{*}$ is largely due to the acceleration of low-level winds. This can be seen by examining the zonal momentum equation near the surface, which can be approximated as $\partial U / \partial t=-\partial \overline{u^{\prime} w^{\prime}} / \partial z=\kappa u_{*}(\partial / \partial z)[z(\partial U / \partial z)]$, where the eddy diffusivity is assumed to be $K_{m}=\kappa z u_{*}$ and the Coriolis term is ignored. The right-hand side can be replaced with $\kappa \overline{u_{*}} / D$, where $D$ is the depth of the surface shear layer. Integrating this equation in time, we obtain the offshore variation of the low-level zonal wind, $U(t)=$ $U_{m}+\Delta U\left(1-e^{-t / T_{R}}\right)$ or $u_{*}(X)=u_{*_{m}}+\Delta u_{*}\left(1-e^{-X / L_{R}}\right)$ (i.e., using $\left.u_{*}=\sqrt{C_{d}} U\right)$, where $T_{R} \sim D /\left(\kappa u_{*}\right)$ and $L_{R} \sim$ $\bar{U} D /\left(\kappa u_{*}\right)$ denote the $e$-folding recovery time and distance, respectively. Taking $D \approx 100 \mathrm{~m}$ and $\overline{u_{*}} \approx 0.1 \mathrm{~m} \mathrm{~s}^{-1}$ (i.e., estimated from the simulation), we have $T_{R} \sim 2500 \mathrm{~s}$ or $L_{R} \sim 8.5 \mathrm{~km}$, which is comparable to the $e$-folding adjustment time (or distance) derived from the $u_{*}$ curve, implying that the increase in $u_{*}$ in the NAZ is predominately due to downward momentum mixing. It is worth noting that variation of the roughness length with wave states and the decoupling described by Mahrt et al. (1998), is not considered in this study.

The CIBL depth increases with the offshore distance, approximately as $Z_{i}=1.85 \sqrt{X+X_{0}}$, where $X_{0} \sim$ $3000 \mathrm{~m}$, which is in reasonable agreement with the COAMPS results. The square-root dependence of $Z_{i}$ on the offshore distance is consistent with previous analytical and observational studies. For example, Hsu (1986) found $Z_{i}=1.9 \sqrt{X}$ based on several datasets, which is in good agreement with our LES and COAMPS results. The sensible heat flux increases from $24 \mathrm{~W} \mathrm{~m}^{-2}$ near shore to $32.5 \mathrm{~W} \mathrm{~m}^{-2}$ at $X=30 \mathrm{~km}$, owing to the increase in both SST and surface wind speed with the offshore distance, and is in reasonable agreement with the COAMPS simulation (Fig. 3). A quantitative comparison between the LES-simulated and measured 


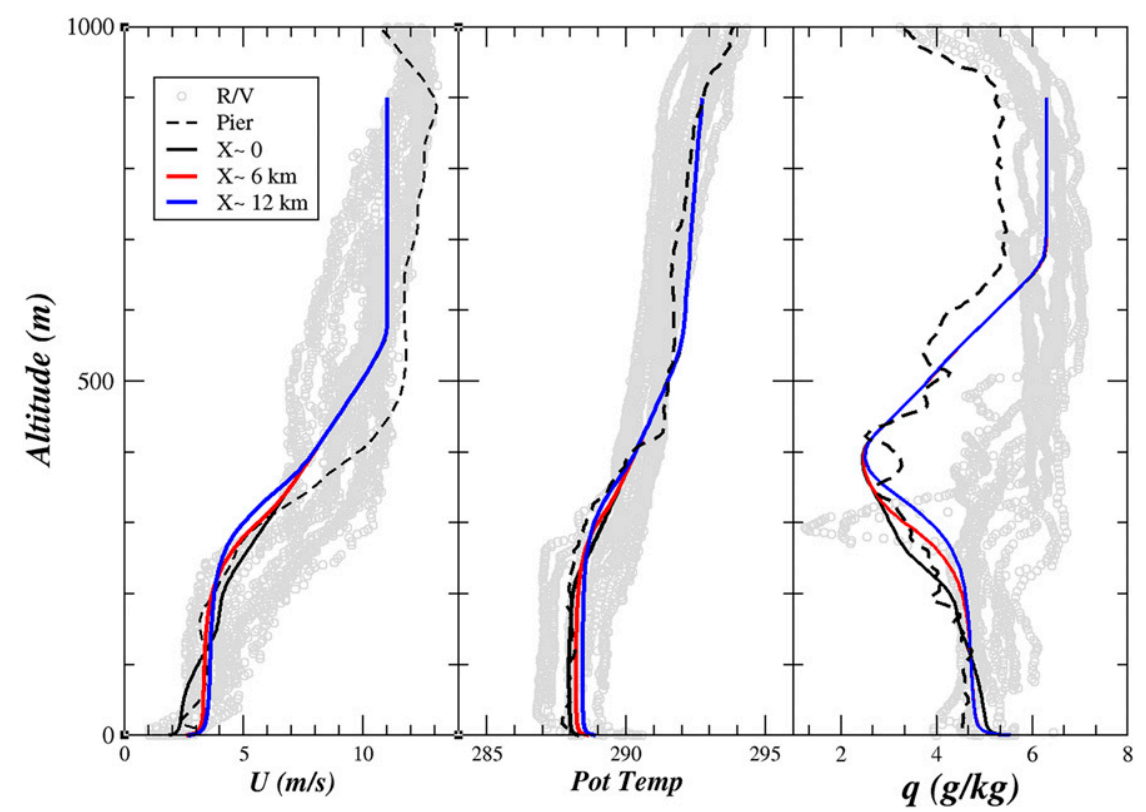

FIG. 6. The domain-averaged profiles of the (left) $u$-wind component $\left(\mathrm{m} \mathrm{s}^{-1}\right)$, (center) potential temperature (K), and (right) specific humidity $\left(\mathrm{g} \mathrm{kg}^{-1}\right)$ at three different offshore locations $(X=0,6$, and $12 \mathrm{~km})$ from the LES control run are shown along with the corresponding profiles from the seven radiosonde measurements. Here the radiosonde profiles from DRP are shown as dashed curves and the ones from the two research vessels are shown as gray circles.

surface fluxes can be found in Table 1. In general, the friction velocity, sensible and latent heat fluxes and the resulting Obukhov length from the LES at the observation location are comparable to the observed. It is worth noting that, although both the sensible and latent heat fluxes increase with the offshore distance, the Obukhov length increases from $\sim-3 \mathrm{~m}$ near shore to $\sim-10 \mathrm{~m}$ at $X=50 \mathrm{~km}$, due to the increase in $u_{*}$. Accordingly, the magnitude of the stability parameter $Z_{\text {ref }} / L$ decreases from more than 2 near shore to 0.7 at $75 \mathrm{~km}$ offshore. The vertically integrated TKE increases sharply immediately offshore, in accordance with the positive heat fluxes and grows farther offshore at a slower rate. However, while the CIBL depth grows steadily, the total TKE exhibits sizable undulations even far offshore, suggesting that the CIBL remains in nonequilibrium throughout the simulation. This is also evident in the fluctuating turbulence budget curves. The total production (i.e., the sum of vertically integrated shear and buoyancy production rates) exceeds the total dissipation over the first $\sim 7 \mathrm{~km}$ offshore, in consistency with the rapid increase of total TKE. Both the production and dissipation rates tend to increase with the offshore distance with the former being slightly larger over most of the time. The difference between the two is relatively small except for several pronounced maxima in the production curves. These maxima are relatively narrow $(<1200 \mathrm{~s}$ or $\sim 5 \mathrm{~km})$ and are approximately in phase with the corresponding maxima in the shear production rate (SPR). In general, the fluctuation in the buoyancy production rate (BPR) is smaller than in SPR and is out of phase with the total production maxima. For example, there are three significant maxima over the last $1.5 \mathrm{~h}$ (Fig. 5), where the buoyancy production rate is nearly $180^{\circ}$ out of phase with the total production. It is worth noting that the last three production rate maxima exceed the corresponding dissipation rate by $30 \%-$ $50 \%$, again suggesting that the simulated CIBL is not in equilibrium even at $75 \mathrm{~km}$ offshore.

The mean profiles of the wind speed, potential temperature, specific humidity, and modified refractivity at three offshore locations (i.e., $X=0,6$, and $12 \mathrm{~km}$ ) are also included in Fig. 6. Near the surface, the wind speed is markedly weaker in NAZ, apparently due to the larger shear stress over land, and becomes well mixed farther offshore. The CIBL depth grows with the offshore distance while the inversion weakens gradually, likely due to the CIBL top entrainment. According to CONTROL, the dry air in the inversion sampled at DRP becomes progressively moister, which is in qualitative agreement with the radiosonde observations (Fig. 6).

In Fig. 7, the simulated profiles near the MAPS measurement location are compared with the mean profiles 


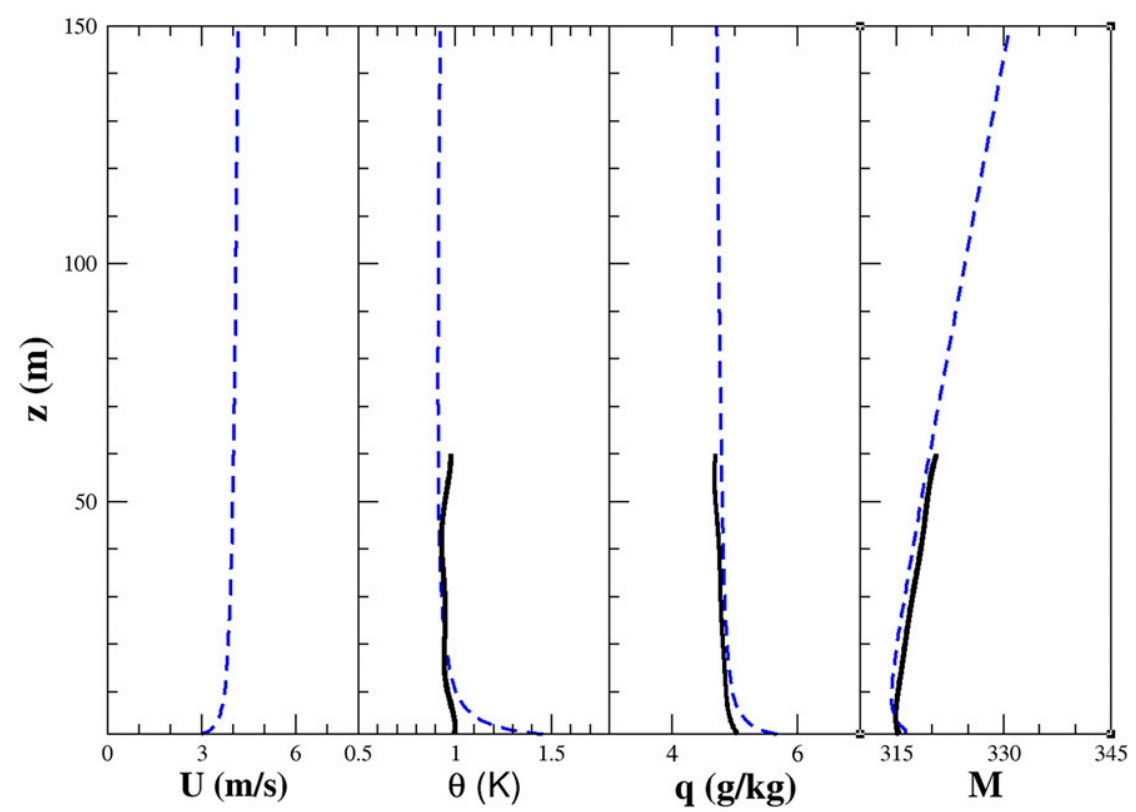

FIG. 7. The domain-averaged (left to right) $u$-wind, potential temperature, specific humidity, and modified refractivity profiles at $X=28.5 \mathrm{~km}$ derived from the LES control run are shown (blue dashed curves) for the lowest $150 \mathrm{~m}$. The corresponding potential temperature, specific humidity, and refractivity profiles from the MAPS measurements (solid black curve) are included for comparison.

from MAPS. The agreement between the LES-simulated and observed profiles are satisfactory except for the first few meters above the surface, where the MAPS measurements might be contaminated by the platform itself. The modified refractivity derived from the LES tends to follow the observed curve and the resulted evaporation duct height is about $1 \mathrm{~m}$ higher than the observed.

Offshore variations of the CIBL structure and turbulence characteristics are further revealed in the fetchheight cross sections in Fig. 8, which are constructed from the domain-averaged profiles at different offshore locations (i.e., approximately every $16 \mathrm{~m}$ ). An underlying assumption for constructing such vertical cross sections is that the large-scale (i.e., synoptic and mesoscale) conditions are steady during the modeling time period. The CIBL, a well-mixed layer capped by an inversion, progressively thickens with the offshore distance while the air in the CIBL gradually becomes warmer and moister. The air in the inversion remains relatively dry over the first $\sim 50 \mathrm{~km}$. Unlike the relatively smooth evolution of the mean fields, the higherorder moments are characterized by episodic variations (Figs. 8d-i). As expected, turbulence is largely confined in the CIBL and tends to strengthen with the offshore distance (Fig. 8d). In addition to large TKE in the surface layer, there is an elevated turbulence layer immediately below the CIBL top inversion. The former is largely attributed to the buoyancy production and the upper one is generated by shear production, owing to the strong vertical wind shear across the inversion (Figs. 8e,f). The elevated TKE maxima and the corresponding shear production rate are more episodic than the buoyancy production rate, with characteristics length scales of 2-6 km (i.e., approximately 10-30 min in time). Approximately in the lower two-thirds of the CIBL, the buoyancy production is positive and becomes progressively larger offshore. In the upper third of the CIBL, the buoyancy production is negative in accordance with the stratification and downward entrainment of warmer air from the inversion. A few negative maxima in the BPR are coincided with the TKE maxima, implying that the TKE maxima have significant contribution to the entrainment of warmer air aloft.

The third-moment of $w$ is in general positive except over the NAZ (i.e., $X<8 \mathrm{~km}$ ), where $\overline{w^{\prime 3}}$ is negative below the elevated TKE maximum, implying substantial downward TKE transport (Fig. 8g), which is consistent with the apparently positive vertical TKE gradient here (Fig. 8d). The TKE aspect ratio, defined as $\mathrm{AR}=2 \overline{w^{12}} /\left(\overline{u^{12}}+\overline{v^{12}}\right)$, where the overbar denotes an area average over the horizontal domain, should be unity for isotropic turbulence. The derived AR is less than unity in the upper portion of the CIBL, presumably due to the stratification effect (Fig. 8h). An elevated 

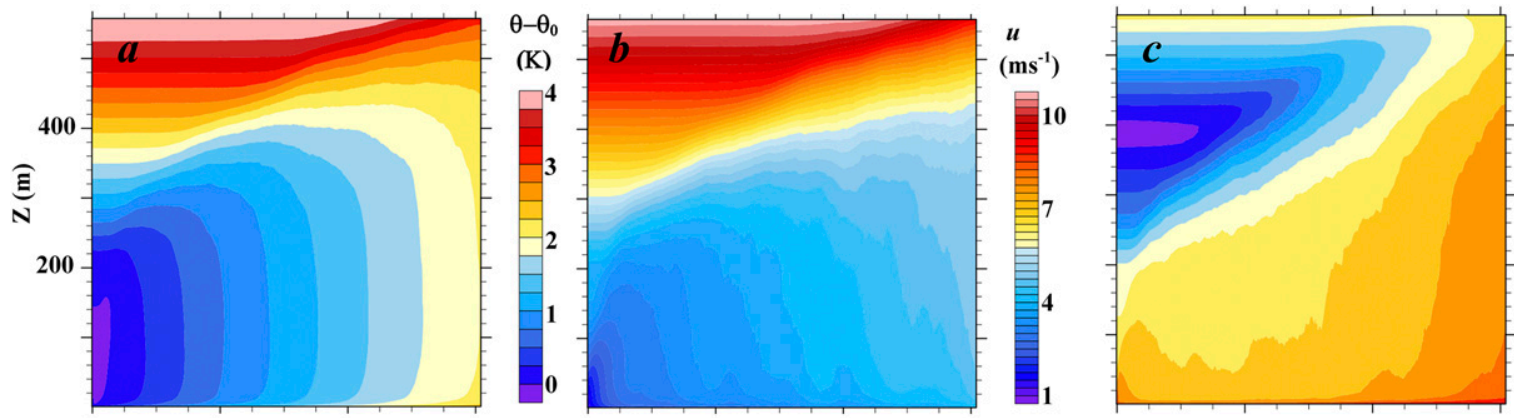

$q$ $\left(\mathrm{gkg}^{-1}\right)$
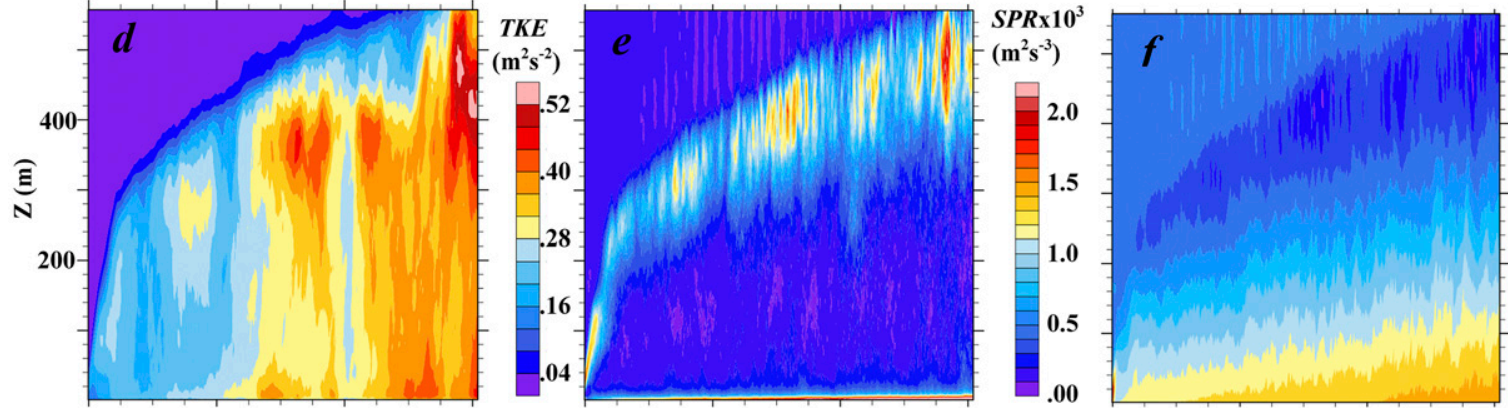

$\left(\mathrm{m}^{2} \mathrm{~s}^{-3}\right)$
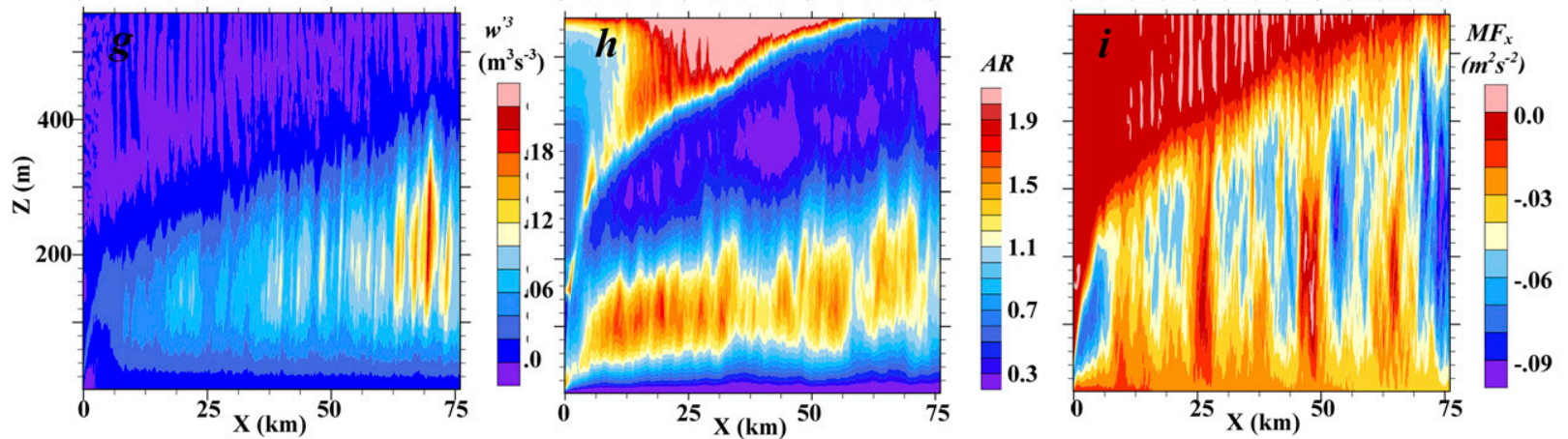

FIG. 8. Offshore distance-height cross sections of (a) potential temperature $\left(\theta-\theta_{0}\right.$, increment $=0.25 \mathrm{~K}$ ), (b) $u$ wind (increment $=$ $\left.0.25 \mathrm{~m} \mathrm{~s}^{-1}\right)$, (c) specific humidity $\left(q\right.$, increment $\left.=0.25 \mathrm{~g} \mathrm{~kg}^{-1}\right),(\mathrm{d})$ turbulence kinetic energy (TKE, increment $\left.=0.1 \mathrm{~m}^{2} \mathrm{~s}^{-2}\right),(\mathrm{e}) \mathrm{shear}$ production rate $\left(\mathrm{SPR} \times 10^{3}\right.$, increment $\left.=0.1 \mathrm{~m}^{2} \mathrm{~s}^{-3}\right)$, (f) buoyancy production rate (BPRx10 $0^{3}$, increment $\left.=0.2 \mathrm{~m}^{2} \mathrm{~s}^{-3}\right)$, $(\mathrm{g})$ third-order moment of $\mathrm{w},\left(\overline{w^{13}}\right.$, increment $\left.=0.02 \mathrm{~m}^{3} \mathrm{~s}^{-3}\right)$, (h) turbulence aspect ratio $(\mathrm{AR}$, increment $=0.1)$, and (i) zonal momentum flux $\left(\mathrm{MF}_{x}\right.$, increment $\left.=0.01 \mathrm{~m}^{2} \mathrm{~s}^{-2}\right)$.

negative momentum flux maximum extends a few kilometers over sea (Fig. 8i), similar to that reported in Vickers et al. (2001). Farther downstream, there is an elevated negative maximum corresponding to each TKE maximum. It is worth noting that, over most of the integration time, the momentum flux divergence is negative in the lower half of the CIBL. In a typical Ekman boundary layer, the momentum equation over a homogeneous surface can be written as (e.g., Jiang et al. 2018),

$$
\frac{\partial U}{\partial t}=-f\left(v-v_{g}\right)-\frac{d \overline{u^{\prime} w^{\prime}}}{d z} .
$$

The variation of the stress divergence with a time scale on the order of $30 \mathrm{~min}$ or less is much faster than the inertial adjustment through Coriolis force (i.e., time scale $\sim 1$ day). Therefore, the Coriolis term is negligible here and the negative momentum flux divergence accelerates the CIBL flow, suggesting that the episodic shear instability and entrainment may have impact on the surface-layer winds through exerting negative momentum divergence.

\section{Validity of MOST over coastal waters}

According to MOST (Monin and Obukhov 1954), over a homogeneous and stationary surface, the nondimensional vertical gradients of horizontal wind speed and scalars and their standard deviations (as well as other higher-order moments) are universal functions of 
the nondimensional height, $\zeta=z / L$ (also referred to as stability parameter); that is,

$$
\begin{aligned}
\frac{\kappa z}{u_{*}} \frac{\partial \bar{U}}{\partial z} & =\varphi_{m}(\zeta), \\
\frac{\kappa z}{\theta_{*}} \frac{\partial \bar{\theta}}{\partial z} & =\varphi_{\theta}(\zeta), \\
\frac{\kappa z}{q_{*}} \frac{\partial \bar{q}}{\partial z} & =\varphi_{q}(\zeta) . \\
\frac{\sigma_{w}}{u_{*}} & =\varphi_{\sigma w}(\zeta), \\
\frac{\sigma_{\theta}}{\theta_{*}} & =\varphi_{\sigma \theta}(\zeta), \\
\frac{\sigma_{q}}{q_{*}} & =\varphi_{\sigma q}(\zeta), \\
s_{w} & =\frac{\left(\overline{w^{13}}\right)^{1 / 3}}{u_{*}}=\varphi_{s w}(\zeta) .
\end{aligned}
$$

Here $z$ is the vertical distance from the surface, $\bar{U}$ and $\bar{\theta}$ denote the horizontally averaged wind speed and potential temperature, $\theta_{*}=-\left(\overline{w^{\prime} \theta^{\prime}}\right)_{0} / u_{*}$ and $q_{*}=$ $-\left(\overline{w^{\prime} q^{\prime}}\right)_{0} / u_{*}$ are the characteristic potential temperature and specific humidity scales, $\sigma_{w}, \sigma_{\theta}$, and $\sigma_{q}$ denote the standard deviations of vertical velocity, potential temperature, and specific humidity, and $s_{w}$ is related to the vertical velocity skewness. On the right-hand side are universal functions of the nondimensional vertical height, $\zeta=z / L$, determined empirically from field observations. The first three equations, often referred to as the flux-gradient relationships, are widely used in numerical weather prediction models to provide surface boundary conditions and in radar wave propagation models to characterize the atmospheric surface layer. Equations (4d)-(4f) are known as variance-profile relationships. Under unstable conditions (i.e., $\zeta<0$ ), the stability functions in (4a)-(4f) can be written as (e.g., Businger et al. 1971; Dyer 1974; Högström 1988)

$$
\begin{aligned}
& \varphi_{m}(\zeta)=a_{1 m}\left(1-a_{2 m} \zeta\right)^{-1 / 4}, \\
& \varphi_{\theta}(\zeta)=\varphi_{q}(\zeta)=\varphi_{h}(\zeta)=a_{1 h}\left(1-a_{2 h} \zeta\right)^{-1 / 2}, \\
& \varphi_{\sigma w}(\zeta)=a_{w 1}\left(1-a_{w 2} \zeta\right)^{1 / 3}, \\
& \varphi_{\sigma \theta}(\zeta)=a_{\theta 1}\left(1-a_{\theta 2} \zeta\right)^{-1 / 3}, \\
& \varphi_{\sigma q}(\zeta)=a_{q 1}\left(1-a_{q 2} \zeta\right)^{-1 / 3} .
\end{aligned}
$$

Several aspects of these functions are worth noting. First, $\zeta$ is the only variable on the right-hand sides and the rest denote empirical constants. For each function, multiple sets of constants have been proposed based mostly on field measurements along with some theoretical considerations. Second, in (5b), the universal functions for potential temperature and specific humidity (as well as other scalars) are often assumed to be identical. However, field observations suggested that the perfect similarity assumption for scalars in the atmospheric surface layer may not always hold, especially over a heterogeneous surface or in a shallow boundary layer (e.g., Katul et al. 2008; Cancelli et al. 2012). The similarity (or dissimilarity) between turbulent transport of temperature and water vapor is evaluated here using the LES data. Third, for $-\zeta \gg 1$, the standard deviations tend to their local free convection scaling limits, namely, $\varphi_{\sigma w} \sim(-\zeta)^{1 / 3}$ and $\varphi_{\sigma \theta}, \varphi_{\sigma q} \sim(-\zeta)^{1 / 3}$, respectively (e.g., Wyngaard et al. 1971; Shao and Hacker 1990).

The nondimensional gradients, standard deviations and skewness at different offshore distances are evaluated using the LES data and shown in Figs. 9-11 along with some reference curves corresponding to some widely used empirical stability functions from field observations over land for comparison. It is worth noting that the averaging methods for the LES data and those from observations are different. The latter are obtained at one or more fixed levels and averaged over a certain time period (e.g., $30 \mathrm{~min}-1 \mathrm{~h}$ ), and the variation in $\zeta$ is largely due to the Obukhov length change. The mean profiles and standard deviations from the LES data are averaged over the horizontal domain (i.e., $512 \times$ 512 grid points) and over 1000 time steps (i.e., $\sim 75 \mathrm{~s}$ ). At each chosen offshore location, the normalized gradients and standard deviations are shown up to $50 \mathrm{~m}$ (i.e., approximately $10 \%$ of the maximum CIBL height) and for $-\zeta<8$. Shown in Figs. 9-11 are the nondimensional gradients and standard deviations every $12.5 \mathrm{~min}$ (i.e., $\sim 2.6 \mathrm{~km}$ ), which are divided into three groups based on their offshore distance, namely, near shore $(X<10 \mathrm{~km}$; colored crosses), medium offshore $(10-40 \mathrm{~km}$; gray circles) and far offshore ( $X>40 \mathrm{~km}$; brown circles).

The nondimensional wind shear from CONTROL shows moderate scatter with the means in reasonable agreement with the Businger et al. (1971) curve. The agreement is poorer for points near the surface (i.e., $-\zeta<0.5)$, where the simulated nondimensional shear in general is larger than the corresponding Businger et al. (1971) prediction (Fig. 9a). The difference is more significant for the nearshore group and less so for the other two groups. For profiles from $X>10 \mathrm{~km}$, while the data points tend to converge, they exhibit comparable scatter 

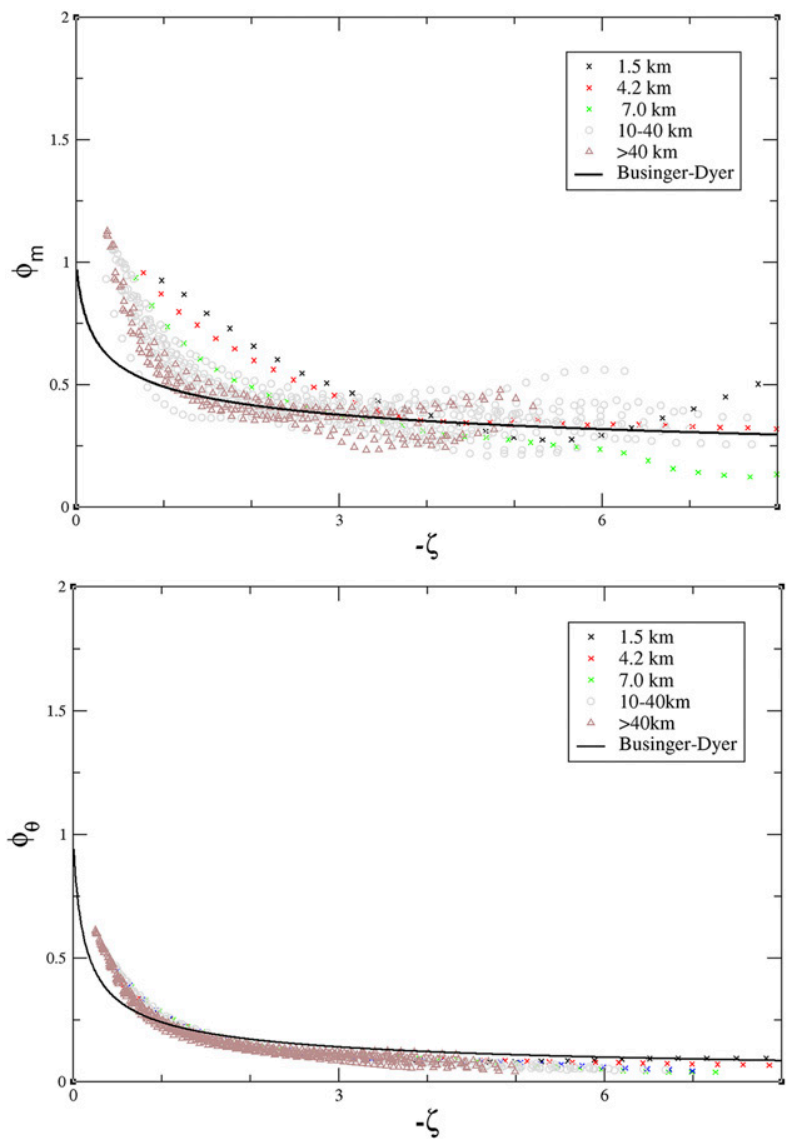

FIG. 9. The nondimensional vertical gradients of (a) horizontal wind speed and (b) potential temperature are plotted vs the negative stability parameter, $\zeta=z / L$. The vertical gradients are evaluated from the LES surface-layer (i.e., $z<50 \mathrm{~m}$ ) profiles averaged over the horizontal domain and $10^{3}$ time steps at 28 different offshore locations. The offshore distance between two adjacent mean profiles is around $2.8 \mathrm{~km}$. The data points are divided into three groups based on their offshore distance, namely, near shore (black, red, and green crosses; $X<10 \mathrm{~km}$ ), intermediate offshore (gray circles; $10<X<$ $40 \mathrm{~km}$ ), and far offshore (brown triangles; $X>40 \mathrm{~km}$ ). The solid lines correspond to Businger-Dyer relationships, $\phi_{m}=(1-16 \zeta)^{-1 / 4}$ and $\phi_{m}=(1-16 \zeta)^{-1 / 2}$ (Kaimal and Finnigan 1994), respectively.

for the two groups, likely in response to the episodic turbulence events evidenced in the vertical cross sections. The nondimensional wind shear in a convective boundary layer from the LES study by Maronga and Reuder (2017) was larger than the corresponding Businger-Dyer prediction as well. Their suggested reasons include deficiencies of SGS models in the underresolved layer, and uncertainties in parameters or constants (such as the von Kármán constant) from previous field observations. In addition, Vickers and Mahrt (1999) observed larger nondimensional wind shears offshore in a relatively shallow CIBL, and pointed to the suppression of largest eddies by the CIBL top as the possible cause.

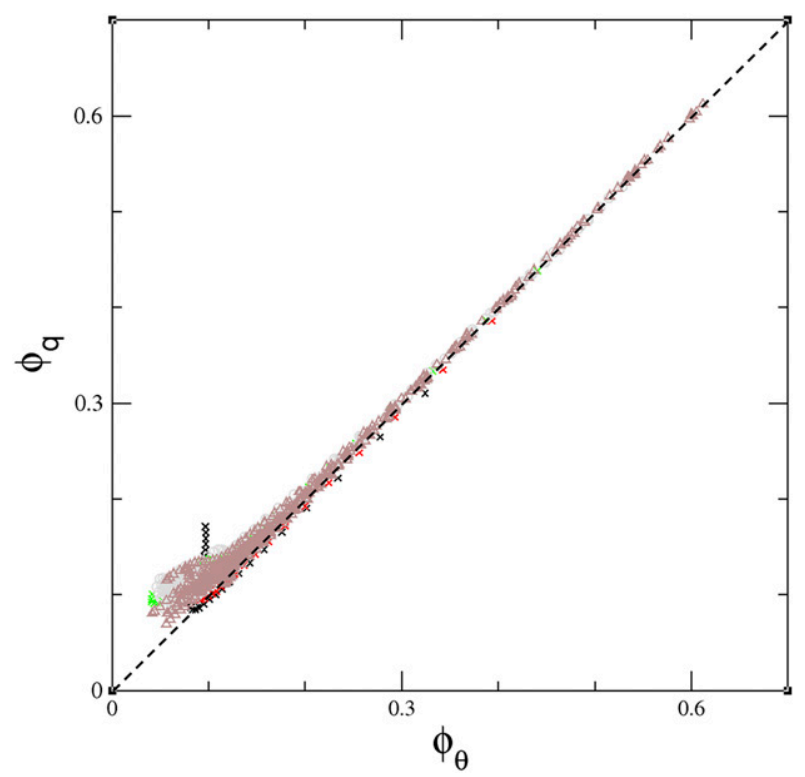

FIG. 10. The nondimensional specific humidity gradient is plotted against the nondimensional potential temperature gradient derived from the same set of mean profiles as in Fig. 9. The dashed line represents perfect similarity between moisture and potential temperature.

Compared to the wind shear, the nondimensional temperature gradients exhibit much less scatter and better agreement with the Businger et al. (1971) curve (Fig. 9b), relatively independent of the offshore distance. Near the surface (i.e., $-\zeta<0.5$, or $z<5 \mathrm{~m}$ ), the LES-simulated nondimensional temperature gradient is noticeably larger than the corresponding Businger et al. (1971) prediction, and the agreement is better for $-\zeta<$ 0.5 . There is nearly perfect similarity between the potential temperature and specific humidity gradients in most of the surface layer for all three groups (Fig. 10). Relatively weak dissimilarity appears near the top of the surface layer (i.e., data points with smaller nondimensional gradients) with the nondimensional specific humidity gradients slightly larger than the corresponding nondimensional potential temperature gradient, suggesting that a small fraction of the surface layer is subject to the influence of processes above the surface layer such as the CIBL top entrainment (Fig. 10).

The normalized standard deviations are shown in Fig. 11. The nondimensional vertical velocity standard deviation is noticeably larger for $X<8 \mathrm{~km}$ and rapidly converges beyond (Fig. 11a), with smaller scatter than its counterpart in the wind shear in Fig. 9a. Overall, most LES data points are located between the curves of Kaimal and Finnigan (1994) and Wilson (2008), except for $-\zeta<0.5$, corresponding to the lowest few model levels. It is worth noting that $\sigma_{w}$ here only includes 

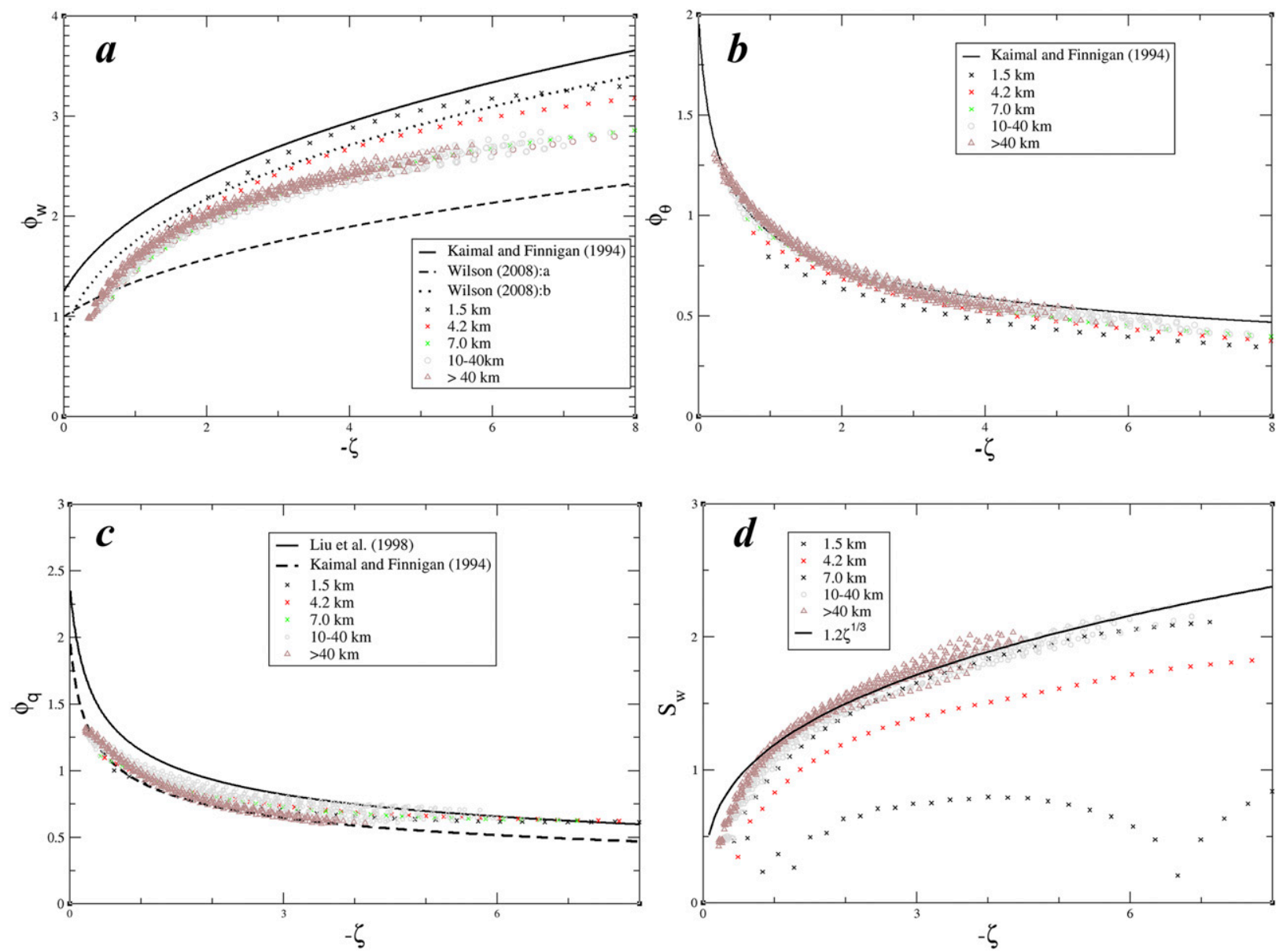

FIG. 11. Nondimensional standard deviations [see (4d)-(4f)] of (a) vertical velocity, (b) potential temperature, and (c) specific humidity are plotted vs the negative Obukhov length. (d) The nondimensional third-order vertical velocity moment is also shown. The mean standard deviations and the third-order $w$ moment profiles are derived from the LES control runs following the same averaging method as in Figs. 9 and 10. The solid curves in (a)-(c) correspond to $\Phi_{w}=1.25(1-3 \zeta)^{1 / 3}, \Phi_{\theta}=2(1-9.5 \zeta)^{-1 / 3}$, and $\Phi_{q}=2.4(1-8 \zeta)^{-1 / 3}(\mathrm{Kaimal}$ and Finnigan 1994), respectively. The solid curve in (d) corresponds to $1.2|\zeta|^{1 / 3}$, derived by the best-fit of data points for the intermediate and far offshore groups. The dashed and dotted curves in (a) correspond to $0.8(1-9.5 \zeta)^{1 / 3}$ and $(1-4.5 \zeta)^{1 / 3}$ (Wilson 2008) and the dashed curve in (c) corresponds to $2.4(1-8 \zeta)^{-1 / 3}$ (Liu et al. 1998).

contributions from resolved turbulence, which tends to zero near a rigid surface. For $-\zeta \gg 1$, the simulated standard deviation tends to $(-\zeta)^{1 / 3}$, which is expected in the local free-convection limit (e.g., Businger 1973). Similarly, the potential temperature standard deviations show reasonable agreement with the corresponding Kaimal and Finnigan (1994) curve with smaller scatter than vertical velocity standard deviations. In addition, the $\varphi_{\sigma \theta}$ derived from the LES run shows better agreement with the Kaimal and Finnigan (1994) prediction in the small $-\zeta$ limit and decreases with increasing $-\zeta$ as $(-\zeta)^{-1 / 3}$. The normalized specific humidity standard deviations behave in a manner similar to the potential temperature standard deviations except that the simulated values are sizably lower than the reference curve from Liu et al. (1998). Using tower observations over farmland, Liu et al. (1998) proposed that $\varphi_{\sigma q}=1.2 \varphi_{\sigma \theta}=$ $2.4(1-8 \zeta)^{-1 / 3}$. Based on an analytical model, Katul and Hsieh (1999) had demonstrated that $\varphi_{\sigma q}>\varphi_{\sigma \theta}$, even when the flux-profile similarity functions for moisture and potential temperature are equal. Their proposed ratio between $\varphi_{\sigma q}$ and $\varphi_{\sigma \theta}$ is 1.32 based on field observations over a homogeneous land surface. On the other hand, Maronga and Reuder (2017) proposed a ratio near unity based on their large-eddy simulations. Our simulations suggest that this ratio varies between 1.05 and 1.2 in a CIBL over sea. Finally, higher-order terms from this LES tend to follow similarity scaling as well. As an example, the variation of the skewness of $w$ (Note the skewness here is defined as $\left(\overline{w^{13}}\right)^{1 / 3} / u_{*}$ as opposed to $\overline{w^{13}} /\left(\overline{w^{12}}\right)^{3 / 2}$ in its conventional definition) with $-\zeta$ is shown in Fig. 11. The skewness is substantially smaller for $X<8 \mathrm{~km}$, associated 

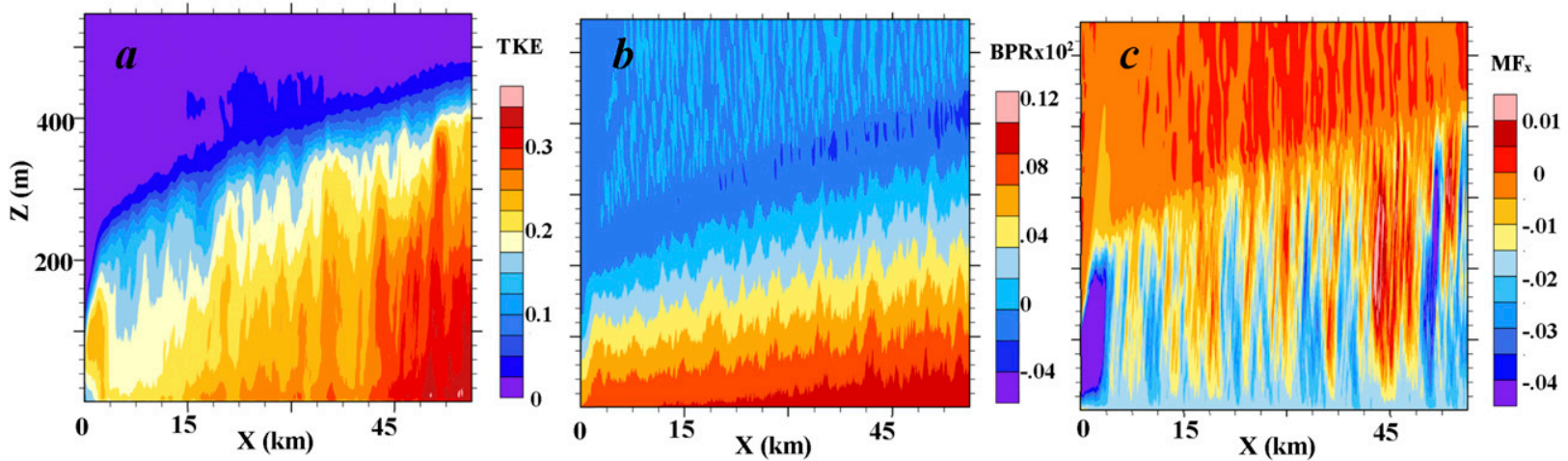

FIG. 12. Fetch-height cross sections of (a) TKE (increment $=0.025 \mathrm{~m}^{2} \mathrm{~s}^{-2}$ ), (b) buoyancy production rate of turbulence (BPR, increment $\left.=0.0002 \mathrm{~m}^{2} \mathrm{~s}^{-3}\right)$, and (c) zonal momentum flux $\left(\mathrm{MF}_{x}\right.$, increment $\left.=0.005 \mathrm{~m}^{2} \mathrm{~s}^{-2}\right)$ from the NOSHEAR simulation.

with downward advection of TKE in the NAZ, and converges farther offshore with relatively small scatter.

In summary, except for over NAZ (i.e., $X<8 \mathrm{~km}$ ), the simulated CIBL follows the MOST scaling reasonably well with relatively small scatter. In general, the standard deviations (or flux-variance relationships) and vertical velocity skewness exhibit smaller scatter than the nondimensional wind shear, which is consistent with previous observations. For example, Grachev et al. (2018) concluded that nondimensional variances tend to follow MOST better than gradients. The relatively large scatter in the nondimensional shear is likely related to the elevated episodic TKE and negative momentum flux maxima.

\section{Discussion}

Although the elevated TKE and momentum flux maxima induced by shear instability are sporadic, the evolution of surface stress and fluxes is rather smooth. An important question arises regarding the marine surface-layer scaling: Does the shear instability aloft have any impact on the surface-layer similarity?

To address this issue, an additional simulation has been conducted with the LES code configured identical to the control except that the vertical shear in the initial $U_{g}$ profile is removed (i.e., NOSHEAR). In NOSHEAR, the airflow is in geostrophic balance with $U_{g}=4 \mathrm{~m} \mathrm{~s}^{-1}$ and $V_{g}=1 \mathrm{~m} \mathrm{~s}^{-1}$. While the simulated mean temperature and moisture cross sections (not shown) are qualitatively similar to those from the CONTROL, the turbulence statistics become noticeably different. First, the significant elevated TKE maxima in CONTROL are absent from NOSHEAR (Fig. 12a). The TKE maxima in NOSHEAR are smaller and the CIBL depth is lower than in CONTRL. For NOSHEAR, the shear production rate is relatively steady and concentrated only in a shallow layer above the surface (not shown). Beyond NAZ, the total integrated turbulence production rate exhibits much smaller fluctuation with time and is in better balance with the dissipation, suggesting that the turbulence in NOSHEAR is closer to an equilibrium state than that in the control simulation. The vertical divergence of the momentum flux and the acceleration of the zonal wind in CIBL are much less significant than in CONTROL.

It is interesting to compare the nondimensional shear, scalar gradients, and standard deviations from NOSHEAR shown in Figs. 13-15 with those from CONTROL in Figs. 9-11. Beyond NAZ (i.e., $X>$ $8 \mathrm{~km}$ ), the nondimensional shears and scalar gradients tend to converge onto their corresponding universal curves, suggesting that, to a good approximation, MOST is valid. For the wind shear, the data points from NOSHEAR exhibit less scatter and the mean curve is closer to the Businger et al. (1971) curve in the small $-\zeta$ limit than their counterparts from the control simulation. The same is true for the nondimensional potential temperature gradient, suggesting that the CIBL top wind shear have substantial impact on the marine surface-layer characteristics. As evidenced in Fig. 14, in the lower half of the surface layer (i.e., larger gradients), the specific humidity and potential temperature exhibit nearly perfect similarity. For the upper portion of the surface layer, the dissimilarity is more evident for $X<40 \mathrm{~km}$ and less so farther offshore (i.e., brown circles). Overall, the nondimensional higher-order moments show reasonable agreement with MOST predictions except for NAZ, and less sensitivity to the impact of the elevated shear layer than the mean shear (or scalar gradients, Fig. 15).

Finally, the fetch-height cross sections of modified refractivity from the two simulations are shown in Fig. 16. In the control simulation, for $X<20 \mathrm{~km}$, there are two ducts for radio waves; an evaporation duct near the surface (i.e., ED height $<10 \mathrm{~m}$ ), and an elevated 

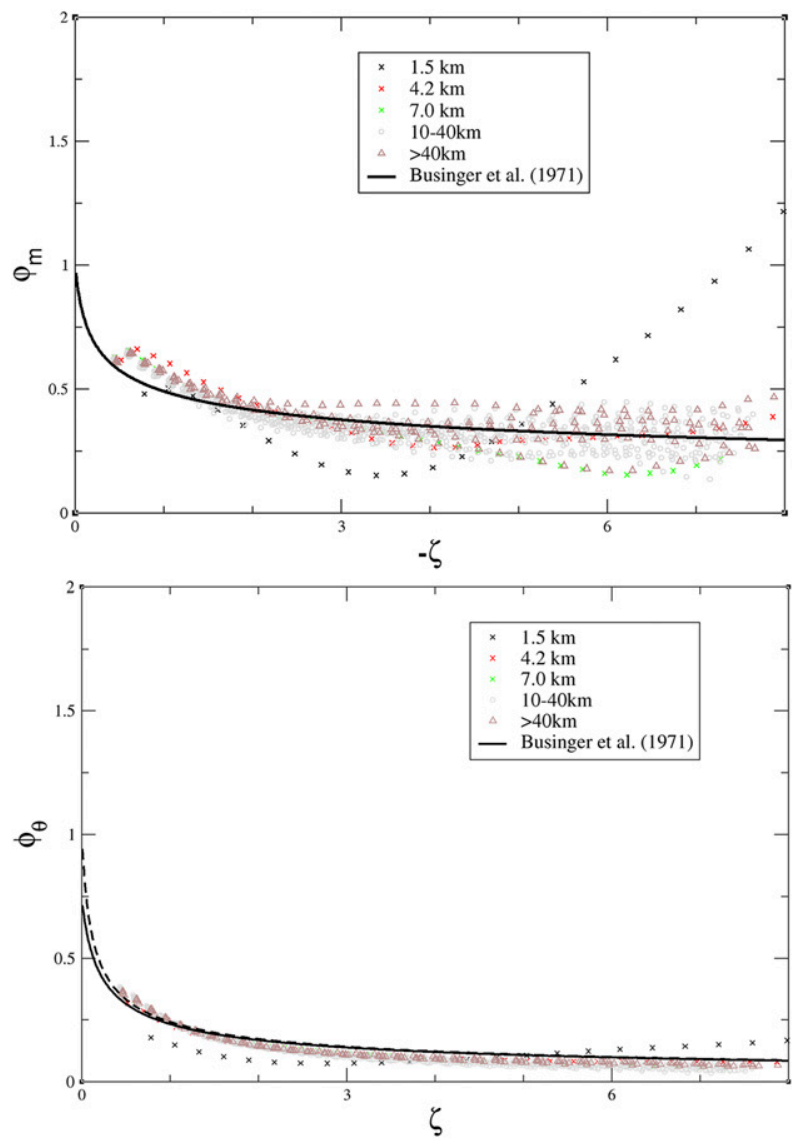

FIG. 13. As in Fig. 9, but for the NOSHEAR simulation.

duct near the inversion, where a specific humidity minimum is present. The latter disappears approximately at $X=20 \mathrm{~km}$ and beyond in CONTROL, presumably due to stronger vertical mixing or entrainment associated with the strong vertical wind shear. The elevated duct weakens some but persists to the end of the simulation in the NOSHEAR run, immunized from moistening associated with shear-induced entrainment. The impact of the wind shear aloft on the evaporation duct height and strength is noticeable but less significant than on the elevated duct.

\section{Concluding remarks}

Turbulence characteristics in a CIBL associated with the advection of cold air over a warmer sea surface are examined using field observations, a mesoscale model simulation and a pair of surface-layer-resolving largeeddy simulations. A Lagrangian modeling approach has been adopted for the LESs, which allows the use of fine grid spacing to better resolve the surface layer while simulating the evolution of the MBL with the offshore distance at an affordable computational cost.

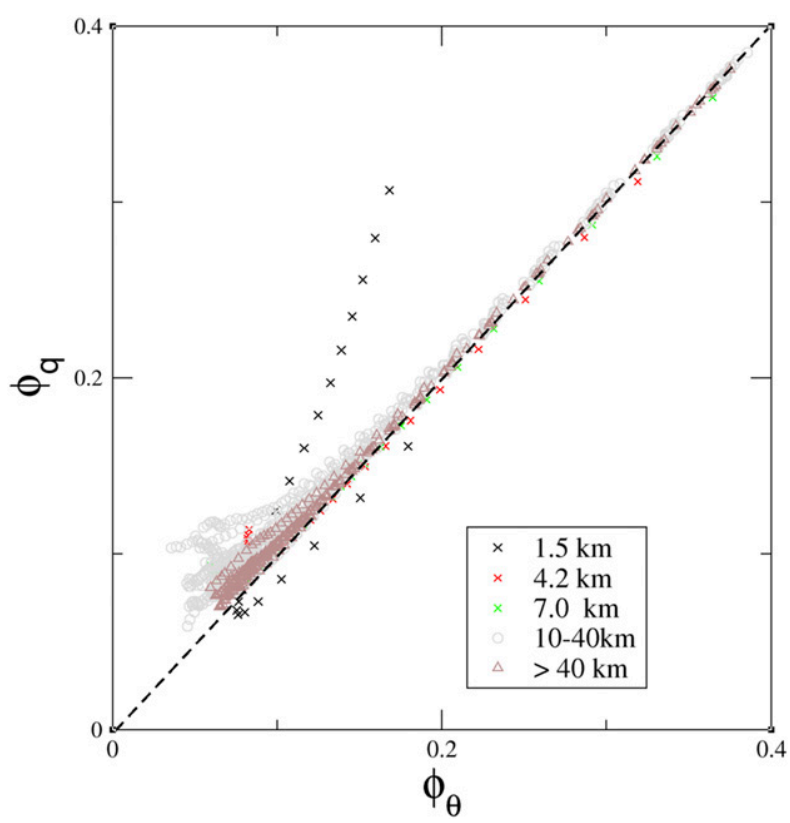

FIG. 14. As in Fig. 10, but for the NOSHEAR simulation.

Both COAMPS and LESs reveal the formation of a CIBL characterized by a turbulent well-mixed layer capped by an inversion. According to the COAMPS simulations and LESs, the CIBL depth grows with the offshore distance $X$ approximately as $\sim Z_{i}=a \sqrt{X+X_{0}}$, where the coefficient $a$ is around 1.6 from COAMPS and 1.9 from the LES control run, which is consistent with previous studies. Here the reference distance, $X_{0}$, is given by $X_{0}=\left(Z_{i 0} / a\right)^{2}$, and $Z_{i 0}$ is the CIBL depth at the coast (i.e., $X=0$ ). The LES-simulated surface fluxes and turbulence characteristics are in reasonable agreement with the CASPER observations. According to the LESs, there is a NAZ extending to approximately $8 \mathrm{~km}$ offshore (i.e., a travel time on the order of $40 \mathrm{~min}$ ), where the surface wind speed and stress increases rapidly in accordance to the discontinuity in the surface stress and fluxes. Within NAZ, the nondimensional vertical shear, scalar gradients, and higher moments deviate substantially from their counterparts farther offshore. The vertical velocity skewness is sizably smaller due to the weakening of turbulence near the surface owing to the sudden decrease in the surface roughness length. It is worth noting that this adjustment process may be further complicated by the variation in the sea state, which is closely coupled with the atmospheric boundary layer (e.g., Vickers and Mahrt 1997, 2010) and likely mesoscale processes.

Beyond NAZ, the nondimensional wind shear, scalar gradients, and standard deviations of vertical velocity and scalars tend to converge onto their corresponding universal curve with relatively small scatter, suggesting that the Monin-Obukhov similarity scaling works reasonably 

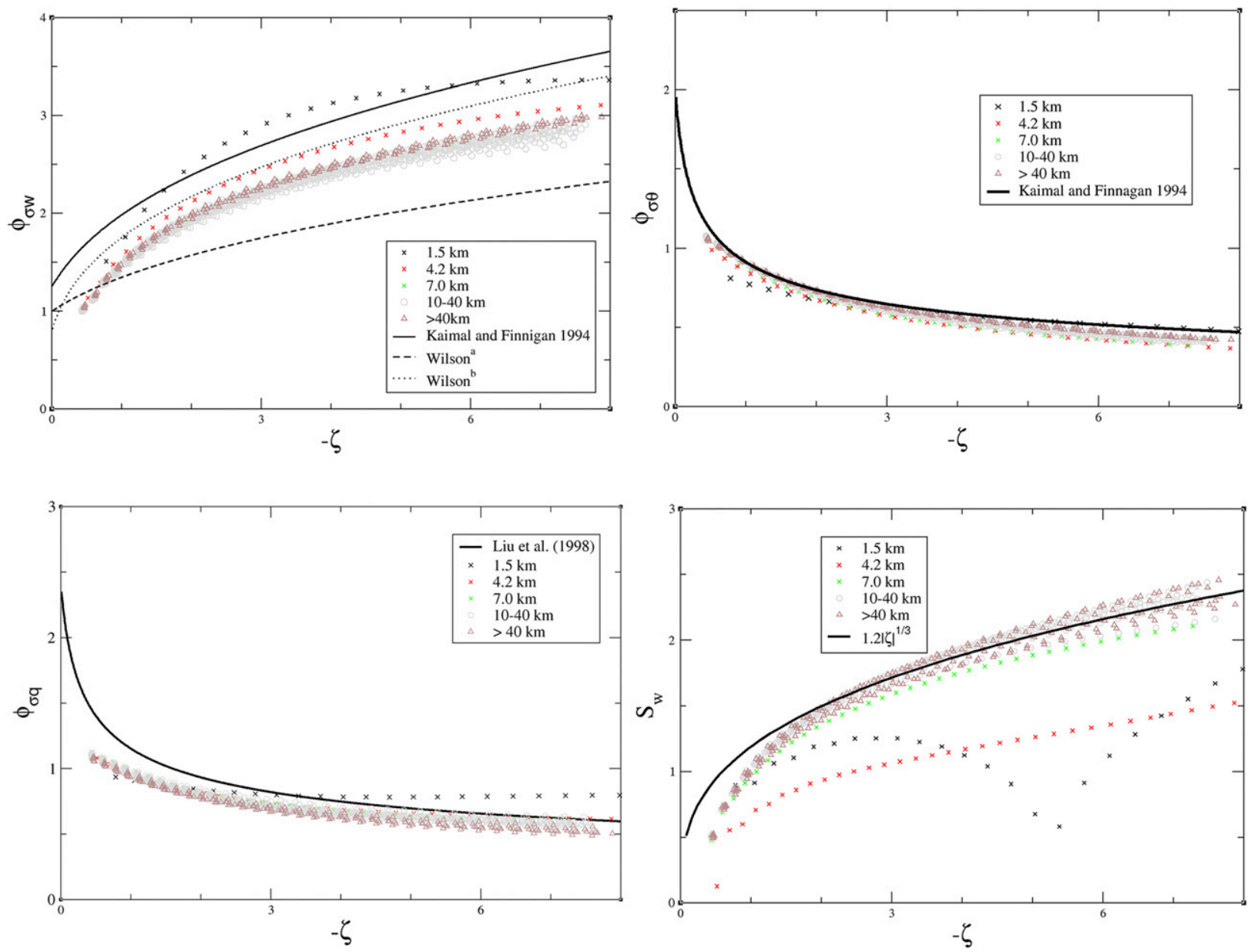

FIG. 15. As in Fig. 11, but for the NOSHEAR simulation.

well with the following caveats. First, while the nondimensional wind shear exhibits substantially larger scatter than the nondimensional scalar gradients and standard deviations, overall, the scatters are rather small than those from field observations, likely due to the idealization of large-scale flows, coastline geometry, and surface conditions in the LESs and also in part due to the different averaging methods. Second, for the control simulation, the mean nondimensional shear and scalar gradients near the surface (i.e., $z<5 \mathrm{~m}$ or $-\zeta<0.5$ ) are noticeably larger than those from previous observations over homogeneous land surfaces, and smaller aloft. Although the differences are rather small compared to typical scatters from observations, these small differences in the scalar gradients may lead to substantial changes in the evaporation duct height prediction. The sensitivity simulation suggests that the difference between LES and observations is at least partially related to the shear instability in an elevated shear layer. Furthermore, the higher-order moments such as the standard deviations of vertical velocity, potential temperature and specific humidity and vertical velocity skewness appear to scale with the nondimensional height $z / L$ better (i.e., with smaller scatters) than the nondimensional wind shear and gradients. They also tend to the local free convection scaling for $-\zeta \gg 1$, suggesting that the fluxvariance relationships are more robust than the fluxprofile relationships in a coastal marine surface layer.

This study highlights the significant impact an elevated shear layer may have on a CIBL structure and associated turbulence characteristics. For the case examined in this study, there is an approximately $7 \mathrm{~m} \mathrm{~s}^{-1}$ increase in the zonal wind component across the thin $(0.3-0.5 \mathrm{~km})$ inversion layer that caps the CIBL, resulting in substantial shear production of TKE inside and below the inversion layer. Several aspects of the elevated shear effect are worth mentioning. First, there is an elevated large TKE layer associated with the shear production aloft, which often exceeds the TKE maximum in the surface layer created primarily by the buoyancy production. Second, the elevated TKE and the correspondence shear production rate are characterized by 

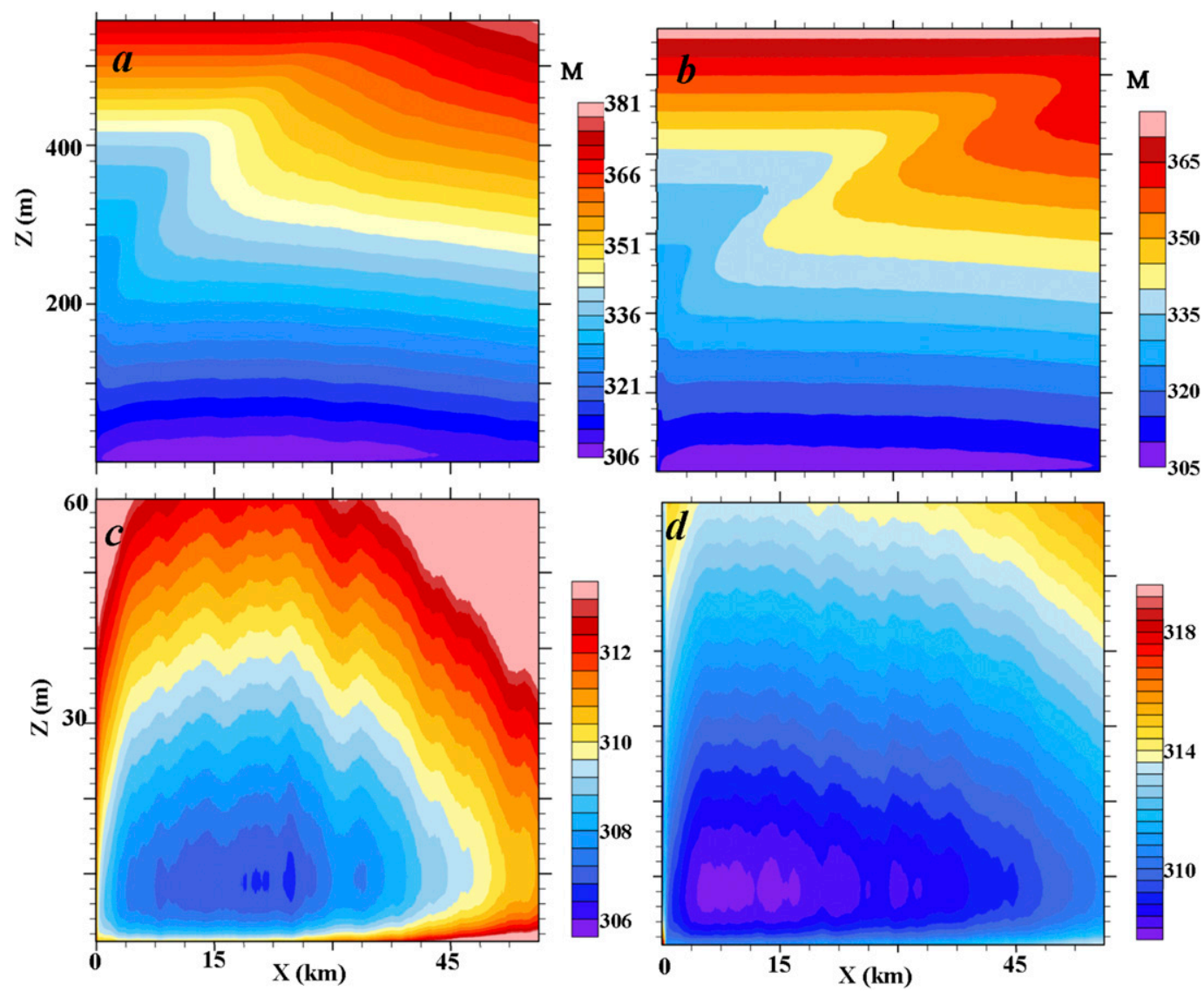

FIG. 16. Fetch-height sections of the modified refractivity from (a) CNTRL (increment = 5) and (c) NOSHEAR (increment $=3$ ) simulations. (c), (d) As in (a) and (b), but for the lowest $60 \mathrm{~m}$ only, with color intervals reduced to 0.4 and 0.8 , respectively.

multiple distinctive maxima with a time scale of around 10-30 min, presumably due to shear instability episodes. Third, during these events, the turbulence production rate exceeds the dissipation rate substantially, implying that the CIBL is still in nonequilibrium even at $75 \mathrm{~km}$ offshore. Fourth, there is a negative zonal momentum flux maximum, approximately coincided with each elevated TKE maximum, indicative of entrainment and downward transport of the zonal momentum. The resulting vertical divergence of zonal momentum flux tends to accelerate the CIBL flow. Furthermore, the BL top entrainment enhanced by the vertical wind shear over the BL top inversion is often observed in a fully developed convective BL, referred to as a "top-down" process or an elevated boundary layer, which may have influence on the surface layer (e.g., Wyngaard and Brost 1984). The influence is more substantial on surface-layer winds and is nonnegligible on scalars in the surface layer, which may lead to errors in evaporation duct predictions using MOST. Finally, the exact offshore locations and occurring frequency of these maxima may be sensitive to the initial wind and stability profiles and may vary from simulations to simulations. The magnitudes of these maxima in TKE and fluxes should be less pronounced if averaging over periods longer their life span (i.e., 10-30 min).

Finally, a couple of limitations of this study are worth noting. First, as pointed out by de Szoeke and Bretherton (2004), potential impact of differential advection associated vertical wind shear is not taken into account in the Lagrangian approach. This is less an issue for the elevated shear layer across the CIBL top inversion, as the faster airflow above the inversion has little direct impact on the CIBL. The thin shear layer immediately above the surface is expected to adjust quickly to the local surface flux forcing and possible impact from differential advection is negligible. Second, mesoscale processes such as landsea breezes may impact the CIBL structure and turbulent characteristics, in part because, according to the COAMPS simulation, mesoscale forcing is relatively weak during the study period. 
Acknowledgments. This research is supported by the Chief of Naval Research through the NRL Base Program PE 0601153N. Dr. Qing Wang acknowledges the support of CASPER project by the Office of Naval Research Multidisciplinary University Research Initiative (MURI; Award N0001419WX01369). Computational resources were supported by a grant of HPC time from the Department of Defense Major Shared Resource Centers. The first author would like to thank Dr. Peter Sullivan at the National Center for the Atmospheric Research for providing us with his LES code.

\section{APPENDIX}

\section{COAMPS Configuration}

COAMPS is a fully compressible, nonhydrostatic terrain-following numerical weather prediction system with a whole suite of physical parameterizations. For the atmospheric model, the finite difference schemes are of second-order accuracy in time and space. The turbulence mixing and diffusion are represented using a prognostic equation for the turbulence kinetic energy budget following Mellor and Yamada (1974) and Thompson and Burk (1991). The surface heat and momentum fluxes are computed following the Louis (1979) and Louis et al. (1982) formulation. The gridscale evolution of the moist processes is explicitly predicted from budget equations for cloud water, cloud ice, rainwater, snowflakes, and water vapor (Rutledge and Hobbs 1983) and the subgrid-scale moist convective processes are parameterized using an approach following Kain and Fritsch (1993). Fu-Liou's $\delta$-four-stream approximation is used for the shortwave and longwave radiation processes (Fu et al. 1997). The atmospheric model is threelevel nested with grid spacings of 9,3 , and $1 \mathrm{~km}$ and the innermost mesh covers a $358 \times 368 \mathrm{~km}^{2}$ area centered at Duck, North Carolina (Fig. 3). There are 60 vertical levels with the model top located at approximately $30 \mathrm{~km}$ MSL, where a radiation condition is applied (Klemp and Durran 1983).

The Navy Coastal Ocean Model (NCOM; Martin 2000 ) is applied to the study area with a horizontal grid spacing of $7.5 \mathrm{~km}$. The atmospheric and ocean models are two-way coupled using the Earth System Modeling Framework (ESMF; Chen et al. 2010).

\section{REFERENCES}

Bean, B. R., and E. J. Dutton, 1968: Radio Meteorology. Dover Publications, $435 \mathrm{pp}$.

Businger, J. A., 1973: A note on free convection. Bound.-Layer Meteor., 4, 323-326, https://doi.org/10.1007/BF02265241.
— J. C. Wyngaard, Y. Izumi, and E. F. Bradley, 1971: Fluxprofile relationships in the atmospheric surface layer. J. Atmos. Sci., 28, 181-189, https://doi.org/10.1175/1520-0469(1971) 028<0181:FPRITA $>2.0$. CO;2.

Cancelli, D. M., N. L. Dias, and M. Chamecki, 2012: Dimensionless criteria for the production-dissipation equilibrium of scalar fluctuations and their implications for scalar similarity. Water Resour. Res., 48, W10522, https://doi.org/10.1029/ 2012 WR012127.

Chang, S. S., and R. R. Braham, 1991: Observational study of a convective internal boundary layer over Lake Michigan. J. Atmos. Sci., 48, 2265-2279, https://doi.org/10.1175/15200469(1991)048<2265:OSOACI $>2.0$.CO;2.

Chen, S., T. J. Campbell, H. Jin, S. Gaberšek, R. M. Hodur, and P. Martin, 2010: Effect of two-way air-sea coupling in high and low wind speed regimes. Mon. Wea. Rev., 138, 3579-3602, https://doi.org/10.1175/2009MWR3119.1.

de Szoeke, S. P., and C. S. Bretherton, 2004: Quasi-Lagrangian large eddy simulations of cross-equatorial flow in the east Pacific atmospheric boundary layer. J. Atmos. Sci., 61, 1837-1858, https://doi.org/10.1175/1520-0469(2004)061<1837: QLESOC $>2.0 . \mathrm{CO} ; 2$.

Dyer, A. J., 1974: A review of flux-profile relationships. Bound.Layer Meteor., 7, 363-372, https://doi.org/10.1007/BF00240838.

Edson, J. B., C. J. Zappa, J. A. Ware, and W. R. McGillis, 2004: Scalar flux profile relationships over the open ocean. J. Geophys. Res., 109, C08S09, https://doi.org/10.1029/ 2003JC001960.

Fairall, C. W., E. F. Bradley, J. Hare, A. Grachev, and J. Edson, 2003: Bulk parameterization of air-sea fluxes: Updates and verification for the COARE algorithm. J. Climate, 16, 571591, https://doi.org/10.1175/1520-0442(2003)016<0571:BPOASF $>$ 2.0.CO;2.

Foken, T., and G. Skeib, 1983: Profile measurements in the atmospheric near-surface layer and the use of suitable universal functions for the determination of the turbulent energy exchange. Bound.-Layer Meteor., 25, 55-62, https://doi.org/ 10.1007/BF00122097.

Fu, Q., K. N. Liou, M. C. Cribb, T. P. Charlock, and A. Grossman, 1997: Multiple scattering parameterization in thermal infrared radiative transfer. J. Atmos. Sci., 54, 2799-2812, https://doi.org/ 10.1175/1520-0469(1997)054<2799:MSPITI>2.0.CO;2.

Garratt, J. R., 1990: The internal boundary layer-A review. Bound.-Layer Meteor., 50, 171-203, https://doi.org/10.1007/ BF00120524.

Grachev, A. A., and C. W. Fairall, 2001: Upward momentum transfer in the marine boundary layer. J. Phys. Oceanogr., 31, 1698-1711, https://doi.org/10.1175/1520-0485(2001)031<1698: UMTITM $>2.0 . \mathrm{CO} ; 2$.

, L. S. Leo, H. J. S. Fernando, C. W. Fairall, E. Creegan, B. W. Blomquist, A. J. Christman, and C. M. Hocut, 2018: Air-sea/ land interaction in the coastal zone. Bound.-Layer Meteor., 167, 181-210, https://doi.org/10.1007/S10546-017-0326-2.

Hertwig, D., L. Burgin, C. Gan, M. Hort, A. Jones, F. Shaw, C. Witham, and K. Zhang, 2015: Development and demonstration of a Lagrangian dispersion modeling system for realtime prediction of smoke haze pollution from biomass burning in Southeast Asia. J. Geophys. Res. Atmos., 120, 12 605-12 630, https://doi.org/10.1002/2015JD023422.

Hodur, R. M., 1997: The Naval Research Laboratory's Coupled Ocean/Atmosphere Mesoscale Prediction System (COAMPS). Mon. Wea. Rev., 125, 1414-1430, https://doi.org/10.1175/15200493(1997)125<1414:TNRLSC > 2.0.CO;2. 
Högström, U., 1988: Non-dimensional wind and temperature profiles in the atmospheric surface layer: A re-evaluation. Bound.-Layer Meteor., 42, 55-78, https://doi.org/10.1007/ BF00119875.

Hsu, S. A., 1986: A note on estimating the height of the convective internal boundary layer near shore. Bound.-Layer Meteor., 35, 311-316, https://doi.org/10.1007/BF00118561.

Jiang, Q., 2020: Influence of swell on marine surface layer structure. J. Atmos. Sci., https://doi.org/10.1175/JAS-D-19-0098.1, in press.

—_, P. Sullivan, S. Wang, J. Doyle, and L. Vincent, 2016: Impact of swell on air-sea momentum flux and marine boundary layer under low-wind conditions. J. Atmos. Sci., 73, 2683-2697, https://doi.org/10.1175/JAS-D-15-0200.1.

_- S. Wang, and P. Sullivan, 2018: Large-eddy simulation study of $\log$ laws in a neutral Ekman boundary layer. J. Atmos. Sci., 75, 1873-1889, https://doi.org/10.1175/JAS-D-17-0153.1.

Kaimal, J. C., and J. J. Finnigan, 1994: Atmospheric Boundary Layer Flows-Their Structure and Measurement. Oxford University Press, 289 pp.

Kain, J. S., and J. M. Fritsch, 1993: Convective parameterization for mesoscale models: The Kain-Fritsch scheme. The Representation of Cumulus Convection in Numerical Models, Meteor. Monogr., No. 46, Amer. Meteor. Soc., 165-170.

Katul, G. G., and C.-I. Hsieh, 1999: A note on the flux-variance similarity relationships for heat and water vapor in the unstable atmospheric surface layer. Bound.-Layer Meteor., 90, 327-338, https://doi.org/10.1023/A:1001747925158.

, A. Sempreviva, and D. Cava, 2008: The temperaturehumidity covariance in the marine surface layer: A onedimensional analytical model. Bound.-Layer Meteor., 126, 263-278, https://doi.org/10.1007/s10546-007-9236-z.

Klemp, J. B., and D. R. Durran, 1983: An upper boundary condition permitting internal gravity wave radiation in numerical mesoscale models. Mon. Wea. Rev., 111, 430-444, https://doi.org/ 10.1175/1520-0493(1983)111<0430:AUBCPI > 2.0.CO;2.

Konstanzer, G. C., 1994: Sensitivity of AN/SPY-1B propagation to evaporation duct heights. JHU/APL Tech. Rep. F2F-94-U-4$012,34 \mathrm{pp}$.

Liu, X., O. Tuskamoto, T. Oikawa, and E. Ohtaki, 1998: A study of correlations of scalar quantities in the atmospheric surface layer. Bound.-Layer Meteor., 87, 499-508, https://doi.org/ 10.1023/A:1000947709324.

Louis, J. F., 1979: A parametric model of vertical eddy fluxes in the atmosphere. Bound.-Layer Meteor., 17, 187-202, https:// doi.org/10.1007/BF00117978.

— M. Tiedtke, and J. F. Geleyn, 1982: A short history of the operational PBL parameterization at ECMWF. Proc. Workshop on Planetary Boundary Layer Parameterization, Reading, United Kingdom, ECMWF, 59-79.

Mahrt, L., D. Vickers, J. Edson, J. Sun, J. Hojstrup, J. Hare, and J. Wilczak, 1998: Heat flux in the coastal zone. Bound.-Layer Meteor., 86, 421-446, https://doi.org/10.1023/A:1000784219817.

Maronga, B., and J. Reuder, 2017: On the formulation and universality of Monin-Obukhov similarity functions for mean gradients and standard deviations in the unstable surface layer: Results from surface-layer-resolving large-eddy simulations. J. Atmos. Sci., 74, 989-1010, https://doi.org/10.1175/JAS-D-16-0186.1.

Martin, P. J., 2000: A description of the Navy Coastal Ocean model version 1.0. Naval Research Laboratory Tech. Rep. NRL/FR/7322-00-9962, 42 pp.

Mason, P. J., and D. J. Thomson, 1992: Stochastic backscatter in large-eddy simulations of boundary layers. J. Fluid Mech., 242, 51-78, https://doi.org/10.1017/S0022112092002271.
Mellor, G. L., and T. Yamada, 1974: A hierarchy of turbulence closure models for planetary boundary layers. J. Atmos. Sci., 31, 1791-1806, https://doi.org/10.1175/1520-0469(1974)031<1791: AHOTCM $>2.0 . C O ; 2$.

Moeng, C. H., 1984: A large-eddy-simulation model for the study of planetary boundary-layer turbulence. J. Atmos. Sci., 41, 2052-2062, https://doi.org/10.1175/1520-0469(1984)041<2052: ALESMF $>2.0 . C O ; 2$.

Monin, A. S., and A. M. Obukhov, 1954: Basic laws of turbulent mixing in the atmosphere near the ground. Tr. Geofiz. Inst., Akad. Nauk SSSR, 24, 163-187.

Raynor, G. S., P. Michael, R. M. Brown, and S. Sethuraman, 1975: Studies of atmospheric diffusion from a nearshore oceanic site. J. Appl. Meteor., 14, 1080-1094, https://doi.org/10.1175/ 1520-0450(1975)014<1080:SOADFA $>2.0$.CO;2.

- S. Sethuraman, and R. M. Brown, 1979: Formation and characteristics of coastal internal boundary layers during onshore flows. Bound.-Layer Meteor., 16, 487-514, https:// doi.org/10.1007/BF03335386.

Rutledge, S. A., and P. V. Hobbs, 1983: The mesoscale and microscale structure of organization of clouds and precipitation in midlatitude cyclones. VIII: A model for the "seeder-feeder" process in warmfrontal rainbands. J. Atmos. Sci., 40, 1185-1206, https://doi.org/ 10.1175/1520-0469(1983)040<1185:TMAMSA $>2.0 . C O ; 2$.

Schubert, W. H., J. S. Wakefield, E. J. Steiner, and S. K. Cox, 1979: Marine stratocumulus convection. Part II: Horizontally inhomogeneous solutions. J. Atmos. Sci., 36, 1308-1324, https:// doi.org/10.1175/1520-0469(1979)036<1308:MSCPIH>2.0.CO;2.

Shao, Y., and J. M. Hacker, 1990: Local similarity relationship in a horizontally inhomogeneous boundary layer. Bound.-Layer Meteor., 52, 17-40, https://doi.org/10.1007/BF00123176.

Skyllingstad, E. D., R. M. Samelson, L. Mahrt, and P. Barbour, 2005: A numerical modeling study of warm offshore flow over cool water. Mon. Wea. Rev., 133, 345-361, https://doi.org/ 10.1175/MWR-2845.1.

Smedman, A.-S., M. Tjernström, and U. Högström, 1994: The nearneutral marine atmospheric boundary layer with no surface shearing stress: A case study. J. Atmos. Sci., 51, 3399-3411, https:// doi.org/10.1175/1520-0469(1994)051<3399:TNNMAB >2.0.CO;2.

Sullivan, P. P., J. C. McWilliams, and C.-H. Moeng, 1994: Subgridscale model for large-eddy simulation of planetary boundarylayer flows. Bound.-Layer Meteor., 71, 247-276, https:// doi.org/10.1007/BF00713741.

-,- , and E. G. Patton, 2014: Large-eddy simulation of marine atmospheric boundary layers above a spectrum of moving waves. J. Atmos. Sci., 71, 4001-4027, https://doi.org/10.1175/ JAS-D-14-0095.1.

Thompson, W. T., and S. D. Burk, 1991: An investigation of an Arctic front with a vertically nested mesoscale model. Mon. Wea. Rev., 119, 233-261, https://doi.org/10.1175/1520-0493(1991)119<0233: AIOAAF $>2.0 . \mathrm{CO} ; 2$.

Ulate, M., Q. Wang, T. Haack, T. Holt, and D. P. Alappattu, 2019: Mean offshore refractive conditions during the CASPER East field campaign. J. Appl. Meteor. Climatol., 58, 853-874, https:// doi.org/10.1175/JAMC-D-18-0029.1.

Vickers, D., and L. Mahrt, 1997: Fetch limited drag coefficients. Bound.Layer Meteor., 85, 53-79, https://doi.org/10.1023/A:1000472623187. , and _ 1999: Observations of non-dimensional wind shear in the coastal zone. Quart. J. Roy. Meteor. Soc., 125, 26852702, https://doi.org/10.1002/qj.49712555917.

— and - 2010: Sea-surface roughness lengths in the midlatitude coastal zone. Quart. J. Roy. Meteor. Soc., 136, 1089 1093, https://doi.org/10.1002/qj.617. 
,,-- J. Sun, and T. Crawford, 2001: Structure of offshore flow. Mon. Wea. Rev., 129, 1251-1258, https://doi.org/10.1175/ 1520-0493(2001)129<1251:SOOF >2.0.CO;2.

Wang, Q., and Coauthors, 2018: CASPER: Coupled Air-Sea Processes and Electromagnetic Ducting Research. Bull. Amer. Meteor. Soc., 99, 1449-1471, https://doi.org/10.1175/BAMS-D16-0046.1.

Wilson, J. D., 2008: Monin-Obukhov functions for standard deviations of velocity. Bound.-Layer Meteor., 129, 353-369, https:// doi.org/10.1007/s10546-008-9319-5.

Wyngaard, J. C., and R. A. Brost, 1984: Top-down and bottomup diffusion of a scalar in the convective boundary layer. J. Atmos. Sci., 41, 102-112, https://doi.org/10.1175/15200469(1984)041<0102:TDABUD>2.0.CO;2.
- O. R. Cote, and Y. Izumi, 1971: Local free convection, similarity and the budgets of shear and heat flux. J. Atmos. Sci., 28, 1171-1182, https://doi.org/10.1175/1520-0469(1971)028<1171: LFCSAT $>2.0 . \mathrm{CO} ; 2$.

Yamaguchi, T., G. Feingold, and J. Kazil, 2017: Stratocumulus to cumulus transition by drizzle. J. Adv. Model. Earth Syst., 9, 2333-2349, https://doi.org/10.1002/2017MS001104.

Yang, Z., and Coauthors, 2019: Measurement-based numerical study of the effects of realistic land topography and stratification on the coastal marine atmospheric surface layer. Bound.-Layer Meteor., 171, 289-314, https://doi.org/10.1007/ s10546-018-00423-2.

Zannetti, P., 1990: Lagrangian dispersion models. Air Pollution Modeling. Springer, 185-222. 